\title{
əFast Storm Surge Ensemble Prediction Using Searching Optimization of a Numerical Scenario Database
}

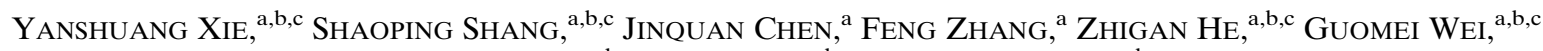 \\ JiNGYU WU, ${ }^{\mathrm{a}, \mathrm{b}, \mathrm{c}}$ BENLU ZHU, ${ }^{\mathrm{d}}$ AND YINDONG ZENG ${ }^{\mathrm{d}}$ \\ ${ }^{\text {a }}$ College of Ocean and Earth Sciences, Xiamen University, Xiamen, China \\ ${ }^{\mathrm{b}}$ Research and Development Center for Ocean Observation Technologies, Xiamen University, Xiamen, China \\ ${ }^{\mathrm{c}}$ Laboratory of Underwater Acoustic Communication and Marine Information Technology, Ministry of Education, \\ Xiamen University, Xiamen, China \\ ${ }^{\mathrm{d}}$ Fujian Marine Forecasts, Fuzhou, China
}

(Manuscript received 6 December 2020, in final form 10 June 2021)

\begin{abstract}
Accurate storm surge forecasts provided rapidly could support timely decision-making with consideration of tropical cyclone (TC) forecasting error. This study developed a fast storm surge ensemble prediction method based on TC track probability forecasting and searching optimization of a numerical scenario database (SONSD). In a case study of the Fujian Province coast (China), a storm surge scenario database was established using numerical simulations generated by 93150 hypothetical TCs. In a GIS-based visualization system, a single surge forecast representing 2562 distinct typhoon tracks and the occurrence probability of overflow of seawalls along the coast could be achieved in 1-2 min. Application to the cases of Typhoon Soudelor (2015) and Typhoon Maria (2018) demonstrated that the proposed method is feasible and effective. Storm surge calculated by SONSD had excellent agreement with numerical model results (i.e., mean MAE and RMSE: 7.1 and $10.7 \mathrm{~cm}$, respectively, correlation coefficient: $>0.9$ ). Tide prediction also performed well with MAE/RMSE of $9.7 / 11.6 \mathrm{~cm}$ versus the harmonic tide, and MAE/RMSE of phase prediction for all high waters of $0.25 / 0.31 \mathrm{~h}$ versus observations. The predicted high-water level was satisfactory (MAE of $10.8 \mathrm{~cm}$ versus observations) when the forecasted and actual positions of the typhoon were close. When the forecasted typhoon position error was large, the ensemble surge prediction effectively reduced prediction error (i.e., the negative bias of $-58.5 \mathrm{~cm}$ reduced to $-5.2 \mathrm{~cm}$ versus observations), which helped avoid missed alert warnings. The proposed method could be applied in other regions to provide rapid and accurate decision-making support for government departments.
\end{abstract}

SIGNIFICANCE STATEMENT: Typhoon storm surge can be a serious hazard to life and infrastructure in coastal areas. However, accurate storm surge prediction is difficult owing to the uncertainty associated with typhoon landfall forecasting. We proposed a multitrack prediction scheme based on a typhoon prediction probability circle. For effective and accurate operational application, we proposed a query optimization method based on a precalculated numerical scenario storm surge database. This method can generate a set of storm surge predictions using 2562 possible typhoon tracks within 2 min. This simple and efficient method could provide accurate and timely results to support decisionmaking in an operational application.

KEYWORDS: Storm surges; Probability forecasts/models/distribution; Decision support

\section{Introduction}

The overflow of seawalls by tropical cyclone (TC) storm surges can cause severe damage in coastal areas (Kentang 2000; Dube et al. 2009; Needham et al. 2015; Kohno et al. (2018); Bloemendaal et al. 2019). According to the Bulletin of China Marine Disasters (Ministry of Ecology and Environment 2020), there were 11 storm surge events in China during 2019 that reached the blue alert level, i.e., $>30 \mathrm{~cm}$ under the local warning level. The total cost of the resultant damage exceeded $\$ 1.76$ billion (U.S. dollars), which is 1.34 times the average value of the past decade, and represented $93 \%$ of the total direct economic

\footnotetext{
๑ Denotes content that is immediately available upon publication as open access.
}

Corresponding author: Shaoping Shang, spshang@xmu.edu.cn losses associated with marine disasters. Therefore, timely and accurate storm surge forecasts are required to support early decision-making regarding the implementation of mitigation measures.

Significant progress in physics-based surge modeling over the previous several decades means it is now possible to simulate storm surge accurately and at high resolution (e.g., Bode and Hardy 1997; Zhang et al. 2007; Westerink et al. 2008; Mattocks and Forbes 2008; Kim et al. 2015). The Advanced Circulation Model for Oceanic, Coastal, and Estuarine Waters (ADCIRC) (Luettich and Westerink 2004), which is one of the models used most commonly for accurate simulation of storm surge, considers the complex physical processes and bathymetric influences using an unstructured grid. However, the uncertainties in typhoon wind field forecasts that are generally used to drive storm surge simulation modeling, might lead to significant errors in storm surge prediction. In recent years, the accuracy of TC forecasts issued by the National Hurricane Center (NHC), 
Japan Meteorological Agency (JMA), China Meteorological Agency (CMA), and other forecasting agencies has steadily improved in their individual areas of responsibility. For example, the mean track forecast errors in the eastern North Pacific for the 2019 season ranged from $46 \mathrm{~km}$ at $12 \mathrm{~h}$ to $248 \mathrm{~km}$ at $120 \mathrm{~h}$ (Cangialosi 2019). The error in operational track forecasts in the western North Pacific and South China Sea for TCs in 2019 was 80 and $127 \mathrm{~km}$ for 24- and 48-h forecasts, respectively (JMA 2019). The mean error in track forecasts from the CMA at $24 \mathrm{~h}$ was $75.7 \mathrm{~km}$ for TCs in 2017 (Chen et al. (2019). However, evidence from recent hurricane seasons in the Western Hemisphere suggests that the rate of improvement in track forecasting has slowed or perhaps even halted (Landsea and Cangialosi 2018). Irrespective of improvements in track forecasting, the errors remain relatively large in terms of accurate storm surge prediction in a small area. Thus, a storm surge prediction produced using only a single deterministic forecast could lead to a missed warning or a warning issued in error when the forecasted TC track deviates markedly from the real track.

The method of ensemble prediction, which has been used widely in recent years, has proven most effective in overcoming the uncertainty in storm surge prediction attributable to TC track forecast error. In ensemble storm surge forecasting, TC tracks are forecasted using numerical models (Flowerdew et al. 2009; Forbes et al. 2014) or created artificially (Krishnamurti et al. 1999; P. T. Wang et al. 2010; Ding et al. 2016) with consideration of the forecast error range based on weather forecast results. The resultant ensemble prediction of TC track is then used to predict storm surge based on simulations using a physics-based surge model. Owing to the notable performance of ensemble prediction, storm surge forecasts based on many ensemble members or multiple scenarios are becoming increasingly important in operational applications (Bonnardot et al. 2016; Greenslade et al. 2017; Hasegawa et al. 2017). The NHC is developing maps of potential storm surge flooding (https://www.nhc.noaa.gov/surge/inundation) that are created from hundreds runs of the Sea, Lake, and Overland Surges from Hurricanes model using official TC tracks, which are developed by hurricane specialists at the $\mathrm{NHC}$ and reflect the large spread in model tracks associated with storms of various intensity, size, and location (Forbes et al. 2014). However, these experimental maps are currently not available until approximately 60-90 min after the release of an NHC advisory. The JMA obtains multiscenario storm surge predictions generated using six TC tracks retrieved through cluster analysis of an ensemble weather prediction system (Hasegawa et al. 2017). Owing to the current TC track forecasting level and storm surge is critically sensitive to landfall position (Irish et al. 2008; Niedoroda et al. 2010), the ensemble prediction issued by several to dozens TC tracks may still miss warning the worst situation. The worst case must be presented to decision-maker to avoid the disaster. Thus the reliability of storm surge ensemble prediction should be improved by increasing the numbers of ensemble members to contain all the possible tracks. The tracks should consider the uncertainty of not only TC forward direction but also TC speed of movement. However, almost all current operational storm surge prediction systems require real-time simulations. Ultimately, it make it difficult for operational organizations to provide timely decisions during consultations that often require rapid response in very short periods (i.e., of the order of seconds to minutes).

As multiensemble predictions generated using physicsbased models have heavy computational burden in operational prediction applications, data-driven and computational intelligence (CI) models with high computational efficiency have been proposed in recent years. An artificial neural network (ANN) is a CI-based approach used widely for prediction and simulation of nonlinear systems, e.g., floods, rainfall, streamflow, and storm surge (Tseng et al. 2007; Wu and Chau 2013; Taormina and Chau (2015); Kim et al. 2015; Fotovatikhah et al. 2018; Kaya et al. 2019; Homsi et al. 2020; Keum et al. 2020). On the basis of a high-fidelity hydrodynamic model, Kim et al. (2015) used ANNs to develop a time-dependent surrogate model, which was shown capable of predicting storm surge with accuracy and significant computational efficiency (i.e., within a few seconds). However, accurate surge prediction with a long lead time (at least $24 \mathrm{~h}$ ) suitable for practical early decision-making support remains limited (Kim et al. 2019; Chao et al. 2020).

The number of members that can be combined in an ensemble is finite owing to the computational requirements of physics-based models. Additionally, data-driven and CI-based models with high computational efficiency are immature owing to the insufficient long-term measurements or a high-fidelity database to produce operational predictions with long lead times. Moreover, professional forecasters are generally required to interpret the model results. Therefore, a fast and robust method for storm surge ensemble prediction comprising a sufficient number of members, is desirable for operational organization. The objective of this study was to develop a reliable ensemble method for fast storm surge prediction based on TC track probability forecasting (Nobutaka 2005; Majumdar et al. 2010) to provide rapid response within periods of seconds to minutes. Considering the urgency of operational decisionmaking procedures, a method with high computational efficiency, i.e., searching optimization of a numerical scenario database (SONSD), was proposed to calculate the ensemble storm surges fast.

The remainder of this paper is organized as follows. In section 2, the proposed method is introduced. Descriptions of the perturbed typhoon forecasts based on the concept of the probability circle, the numerical scenario surge and tide database, and SONSD are included in this section. In section 3, a case study of the application of the new fast ensemble storm surge prediction method to the coast of Fujian Province (China) is presented. In section 4 , the preliminary verification results of the ensemble forecasts are analyzed in comparison with tide gauge data recorded during two actual typhoon events. The advantages and shortcomings realized through use of the proposed method in the case study are discussed in section 5. Finally, our conclusions are presented in section 6 .

\section{Methods}

The fast ensemble forecast method using SONSD consists of three steps: 1) retrieve TC probability forecast locations from 
the probability circles to generate an ensemble of all probable perturbed TC track forecasts; 2) generate all possible hypothetical TCs in the study area, predetermine the storm surge at coastal water points for all hypothetical TCs to establish a scenario numerical storm surge database, and calculate the astronomical tide for coastal water points during a calendar year to establish a tide database to provide rapid estimation of the storm surge associated with the perturbed TC track forecasts; and 3) develop a searching optimization method for storm surge based on the numerical scenario database of step 2 to calculate a group of ensemble surge forecasting members for the TCs in step 1.

\section{a. Perturbed tropical cyclone forecasts}

In consideration of both the substantial impact of TC track forecasts on disaster prevention activities and the unavoidable errors in such forecasts, most national meteorological services present TC track forecasts with a range of possible deviation. The Tokyo Typhoon Center is a Regional Specialized Meteorological Center (RSMC) that adopts the "probability circle" for its TC track forecasts, which is a circular area defining potential TC locations with probability of $70 \%$ at each forecast time. The radius of the probability circle is determined statistically such that $70 \%$ of forecasted positions will fall within the circle (Nobutaka 2005). The annual mean radius of circles defined at the 24- and 48-h forecast positions in 2019 was $93 \mathrm{~km}$ (110 km in 2018) and $162 \mathrm{~km}(203 \mathrm{~km}$ in 2018), respectively (JMA 2019). The cone defined by the NHC track forecast (https://www.nhc.noaa.gov/aboutcone.shtml) represents the probable track of the center of a tropical cyclone, and is formed by enclosing the area swept out by a set of circles along the forecast track (at certain forecast periods, e.g., 12, 24, and $36 \mathrm{~h}$ ). The size of each circle is set such that two-thirds of historical official forecast errors over a 5-yr sample fall within the circle, with values of approximately 90 and $150 \mathrm{~km}$ for 24- and 48-h forecasts, respectively (Cangialosi 2019). The CMA has produced maps of forecast TCs with probability circles since 2007 (http://www.nmc.cn/publish/typhoon/). However, detailed information regarding the probability circles are not included in the TC message delivered to local institutions. According to the mean track forecast error in 2005 , the radius of the probability circles during 2007-08 was determined statistically to be 133 and $223 \mathrm{~km}$ at 24 and $48 \mathrm{~h}$, respectively (Zhang et al. 2010).

To perturb ensemble forecast tracks, the concept of the probability circle is adopted, whereby the circle indicates the range of expected positions of a TC for a given probability. Thus, each dot within the probability circle is considered a possible location of the TC at the forecasted time. With consideration of the radius employed by the national meteorological services mentioned above, the radius of the probability circle adopted in this study was set to 120 and $215 \mathrm{~km}$ at forecast times of 24 and $48 \mathrm{~h}$, respectively. The radii of the probability circles would decrease with reduction of the positional errors of the forecasts achieved through technical improvements. In the case of the 24-h forecast of the track shown in Fig. 1, the probability circle radius was divided into 60 nodes along diameter DE (indicating 60 TC directions) and FG (indicating 60 velocities) with a distance of at most $2 \mathrm{~km}$ between two adjacent points, which is close to the common resolution of storm surge numerical models. Thus, the circle contained 2562 nodes, each of which represented a possible location of the TC center at the 24-h forecast time. Linking one node with the initial TC location produced one perturbed TC forecast track. Therefore, repeating this process for all the nodes within the circle produced an ensemble of almost 2562 groups of perturbed TC forecasts based on one forecast maximum wind speed. These typhoon tracks comprised not only the extreme tracks [i.e., left (AE), right (AD), quick (AF), and slow (AG) tracks] but also almost all possible perturbed TC tracks with higher spatial resolution; thus, avoiding any potential results being missed. Other possible TC intensities, set according to meteorological conditions, could be combined with the perturbed TC tracks to obtain other groups of ensemble perturbed TC parameters.

Similarly, in the case of the 48 -h forecast, the circle contained 2562 nodes, whereby each node represented a possible location of the TC center at the 48-h forecast time. Linking the corresponding 24- and 48-h forecast locations generated the forecasted 24-48-h TC track, e.g., BC, DD', EE', FF', and $\mathrm{GG}^{\prime}$ in Fig. 1 represent the current, right, left, quick, and slow tracks, respectively. By analogy, an ensemble of 2562 groups of perturbed TC forecasts was obtained through combination with one forecasted maximum wind speed at the 48-h forecast time.

\section{b. Numerical scenario storm surge and tide database}

Although the number of perturbed TC forecasts described above is sufficient to obtain an accurate forecasted result, there is considerable computational cost incurred in calculating storm surge for such a large number of perturbed TC forecasts using a physics-based model in real time. Such computational overheads are too great for such an approach to be used by operational centers in some countries, and especially in local provinces and cities. To overcome this problem, a fast searching optimization method is proposed based on a precalculated numerical scenario database generated using hypothetical TCs. With this method, the storm surge and astronomical tide are computed quickly based on an independent database and then superimposed to determine the potential total water level.

\section{1) HYPOTHETICAL TCS}

Irish et al. (2010, 2011) proposed a method using surge response functions that allows rapid algebraic surge calculation by applying high-resolution numerical computation results in the formulation. In this study, the precalculated numerical scenario surge database is proposed as a surge response to multidimensional determining factors. As mentioned in Irish et al. (2010), the peak hurricane surge at a specific location is a function of hurricane-related conditions (e.g., hurricane landfall location, central pressure, radius to maximum wind, forward speed, and track angle with respect to coastline orientation) as well as factors related to regional and local topographic conditions. A group of six storm-related parameters input at each time step was used to predict storm surge using a time-dependent surrogate model (Kim et al. 2015). Therefore, the storm surge at a water point can be assumed to reflect specific TC-related parameters, i.e., the location of its center $(N, E)$, track angle with 


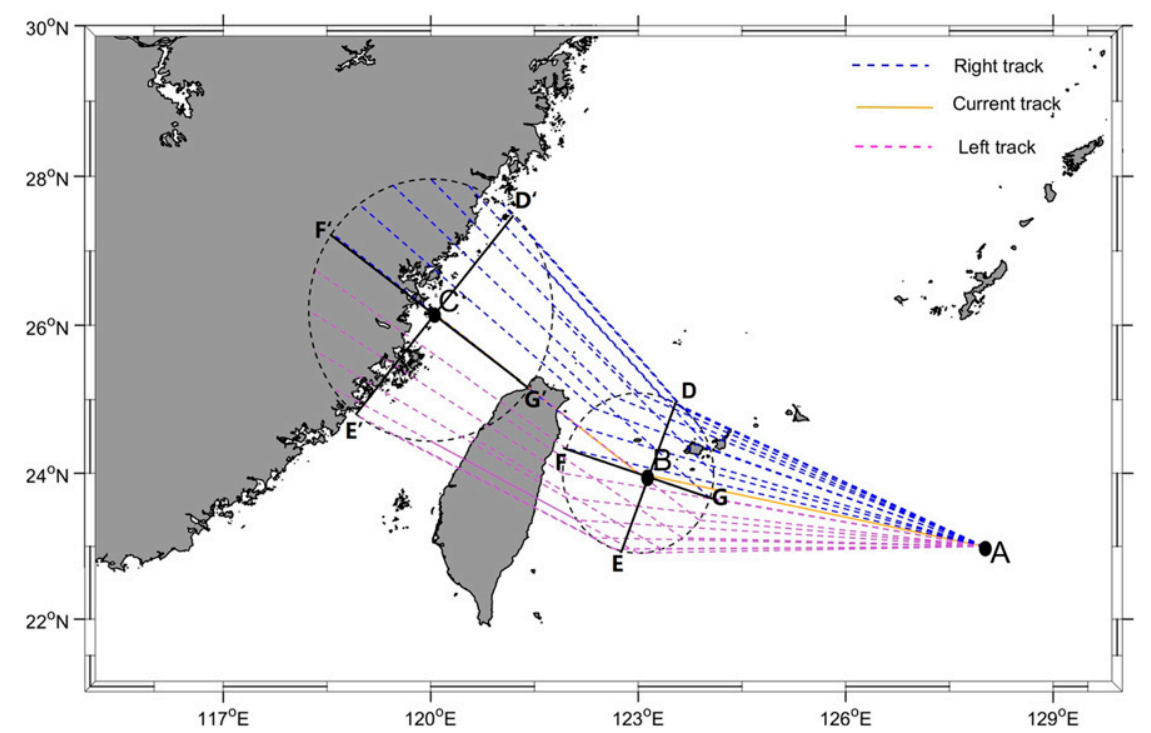

FIG. 1. Ensemble TC tracks based on the concept of the probability circle. Dots A, B, and C represent the initial, 24-h, and 48-h forecast TC central positions, respectively. Dots D, E, F, and $\mathrm{G}$ and dots $\mathrm{D}^{\prime}, \mathrm{E}^{\prime}, \mathrm{F}^{\prime}$, and $\mathrm{G}^{\prime}$ represent the right, left, quick, and slow 24- and 48-h forecast TC central positions, respectively.

respect to coastline orientation $(\alpha)$, forward speed $(V)$, maximum wind speed $\left(W_{\max }\right)$, central pressure drop $(\mathrm{dp})$, and radius of maximum wind $\left(R_{\max }\right)$. One combination of these parameters should be sufficient for a wind and pressure model. However, the size of the precalculated database generated by the TC combinations of selected storm parameters would directly influence the efficiency and convenience of the calculation method in practical application. If all the above TC parameters were combined in the database, its size would be too large for convenient application. Therefore, the correlation between parameters was analyzed as follows to minimize the number of combined parameters.

First, the central pressure drop and maximum wind speed, which are both indicators of TC intensity, exhibit certain correlation for mature TCs at sea (Atkinson and Holliday 1977). Best track data of regional TCs were collected from the CMA website (http://www.tcdata.typhoon.org.cn) (Ying et al. 2014). These data comprised time, $N, E, W_{\max }$, and central pressure. Using the best track data of the 122 typhoons that occurred in the Northwest Pacific and around Taiwan during 1950-2008, the relationship between $W_{\max }$ and dp of the typhoons [Eq. (1)] was determined (Fig. 2):

$$
\mathrm{dp}=0.0124 \times W_{\max }^{2}+0.634 \times W_{\max }-4.634
$$

Second, the radius of maximum wind speed, which is one of the principal standards for expressing the horizontal scale of a TC, is also one of the most critical parameters used in a model of a TC wind field. However, it is not given as one of the real-time forecast parameters issued by major meteorological agencies or in real-time observations. The usual method is to search for empirical or statistical functions related to other forecast parameters (Hsu and Yan 1998; Willoughby and Rahn 2004; Chen 2006). This study adopted the common function related to maximum wind and latitude used by Willoughby and Rahn (2004) after evaluating the storm surge simulation performance with different function, i.e., the statistic relation given by Chen (2006) as well as by Willoughby and Rahn (2004).

Consequently, five independent parameters $(N, E, \alpha, V$, and $\left.W_{\text {max }}\right)$ were thus combined for the hypothetical TCs in the proposed method. Taking the coast of Fujian Province as a case study, the ranges of the five typhoon parameters were also determined based on the statistics of the best track data of the 122 typhoons mentioned above. The maximum wind speed was specified in the range of $25-70 \mathrm{~m} \mathrm{~s}^{-1}$ at intervals of $5 \mathrm{~m} \mathrm{~s}^{-1}$. Also, the central locations (intervals of $0.1^{\circ} \times 0.1^{\circ}$ ) of typhoons

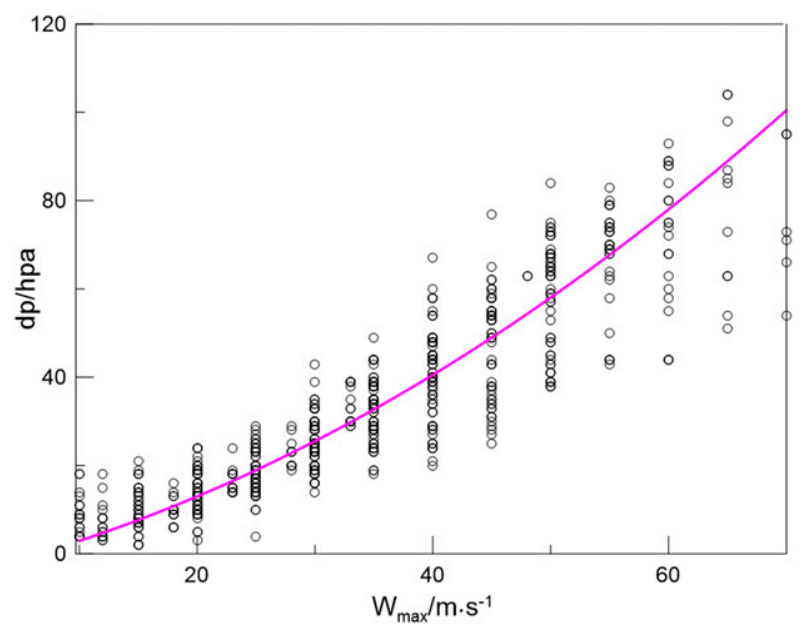

FIG. 2. Relationship between central pressure drop (dp) and maximum wind speed $\left(W_{\max }\right)$ of typhoons around the Taiwan Strait. 


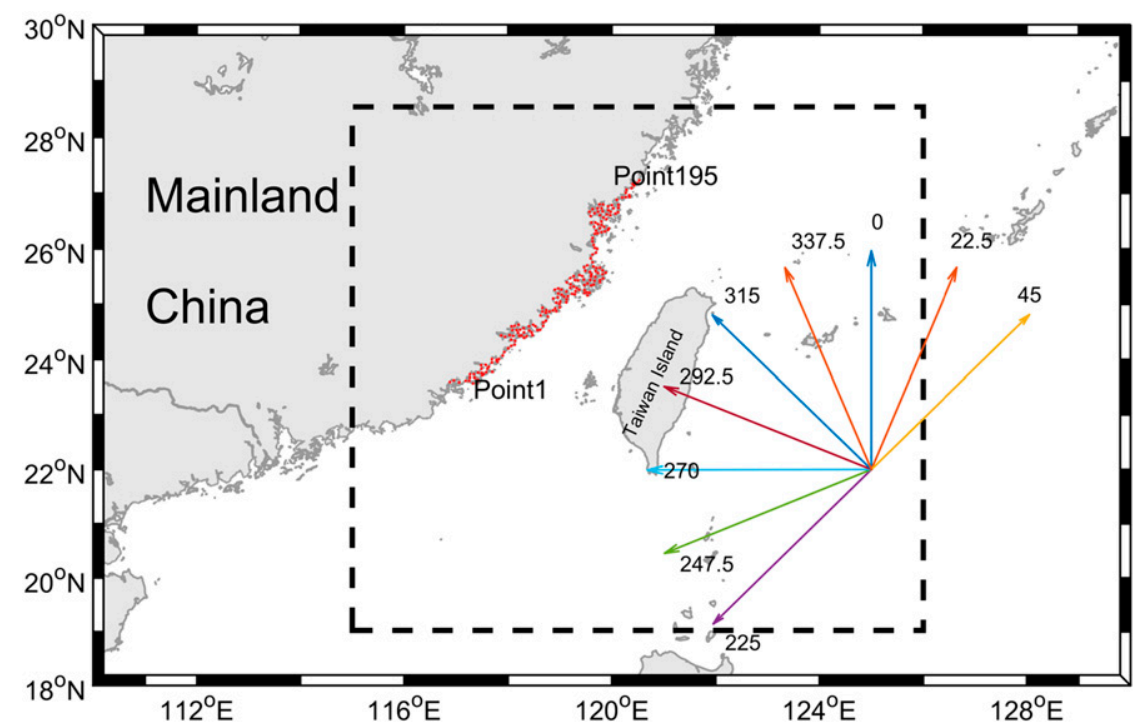

FIG. 3. Ranges of the typhoon parameters in relation to the coast of Fujian Province. The black dotted rectangle represents the area of central locations of typhoons. Red dots ranging from "Point 1" to "Point 195" along the coast of Fujian Province represent the water points computed by the model. Colored arrows show the track angles.

that could induce a surge of $>20 \mathrm{~cm}$ along the coast of Fujian Province were determined to be in the rectangle $\left(19^{\circ}-28.5^{\circ} \mathrm{N}\right.$, $\left.115^{\circ}-126^{\circ} \mathrm{E}\right)$ shown in Fig. 3. Overall, nine track angles were defined (with $0^{\circ}$ to the north) together with five forward speed ranges of $0.05^{\circ}-0.45^{\circ} \mathrm{h}^{-1}$ with intervals of $0.1^{\circ} \mathrm{h}^{-1}$. Consequently, 10 maximum wind speeds, 5 forward speeds, 9 track angles, and $96[=(28.5-19) / 0.1+1]$ plus $111[=(126-115) / 0.1+1]$ track beginning locations, specified as latitude and longitude, were taken into account. One hypothetical TC was determined for each case of the five parameters defined; thus, $93150[=10 \times$ $5 \times 9 \times(111+96)]$ hypothetical TCs were generated.

\section{2) NUMERICAL SCENARIO STORM SURGE}

Any single well-calibrated model could be used to calculate a storm surge database for a study area. There are several storm surge numerical models in common use, e.g., ADCIRC (Luettich and Westerink 2004; Feng et al. 2018) and the Unstructured-Grid, Finite-Volume Coastal Ocean Model (FVCOM) (Chen et al. 2006). Additionally, Zhang et al. (2007), Xie et al. (2009), and Zhang et al. (2020) developed regional numerical models for the Taiwan Strait with coupling of different physical processes. As storm surge is calculated independently in our proposed method, a simple one-way nested pure storm surge numerical model (Xie et al. 2009) was used to calculate surge for the hypothetical TCs. The adopted model incorporated two-dimensional shallow-water equations including the depth-averaged continuity equation and momentum equations in quasi rectangular coordinates. The coarse mesh domain $\left(18^{\circ}-30^{\circ} \mathrm{N}, 110^{\circ}-130^{\circ} \mathrm{E}\right)$ with grid size of $1 / 10^{\circ}$ and the fine mesh domain $\left(22.0^{\circ}-28.4^{\circ} \mathrm{N}\right.$, $\left.113.3^{\circ}-121.5^{\circ} \mathrm{E}\right)$ cover the coastal area around the Taiwan Strait with fine grid precision of $1 / 30^{\circ}$. The model was forced by a wind field model established by Chen (2006), which consists of a circular symmetric wind field (Holland 1980), dynamic typhoon wind field (Jelesnianski 1965), and an additional wind field that considers the influence of the Taiwan Strait and Taiwan. The atmospheric pressure field for the TC was calculated using formulas given by Holland (1980) and Jakobsen and Madsen (2004). The wind stress coefficient (drag coefficient) was determined based on that used by Zhang et al. (2007). Overall, 31 storm surge events induced by typhoons (shown in Fig. 4), which occurred during 1969-2001, were simulated to evaluate the storm surge modeling performance. Comparison with measured data from five tide gauges (locations shown in Fig. 2) revealed that the model performed well with mean absolute error (MAE) and root mean squared error (RMSE) of 21.2 and $23.2 \mathrm{~cm}$, respectively, calculated statistically for surges 2 days both before and after the peak surge during the 31 storm surge events. Given that it is always a large surge that causes disaster, the simulation performance of both the peak surge (MAE and RMSE: 21.5 and $26.4 \mathrm{~cm}$ ) and the phase error (MAE and RMSE: 2.4, 3.3 h) was also evaluated.

The model used a 30-s time step internally, interpolated the input typhoon parameters in time and space, and generated elevation outputs of the hypothetical TCs with an interval of $0.1^{\circ}$ for each typhoon location along the track. The storm surge at 195 water points (red dots along the coast in Fig. 4) calculated for each hypothetical TC was recorded in a netCDF file. Each element of recorded elevation information contained the surge at the 195 coastal water points and the relevant TC parameters (i.e., $N, E, W_{\max }, \alpha$, and $V$ ). Consequently, this quantity of combined TC parameters for the Fujian Province coast meant that the size of the netCDF database was almost $4 \mathrm{~GB}$.

\section{3) Astronomical tide database}

The astronomical tide has only one level at a time because it does not depend on meteorology for a water point. Therefore, 


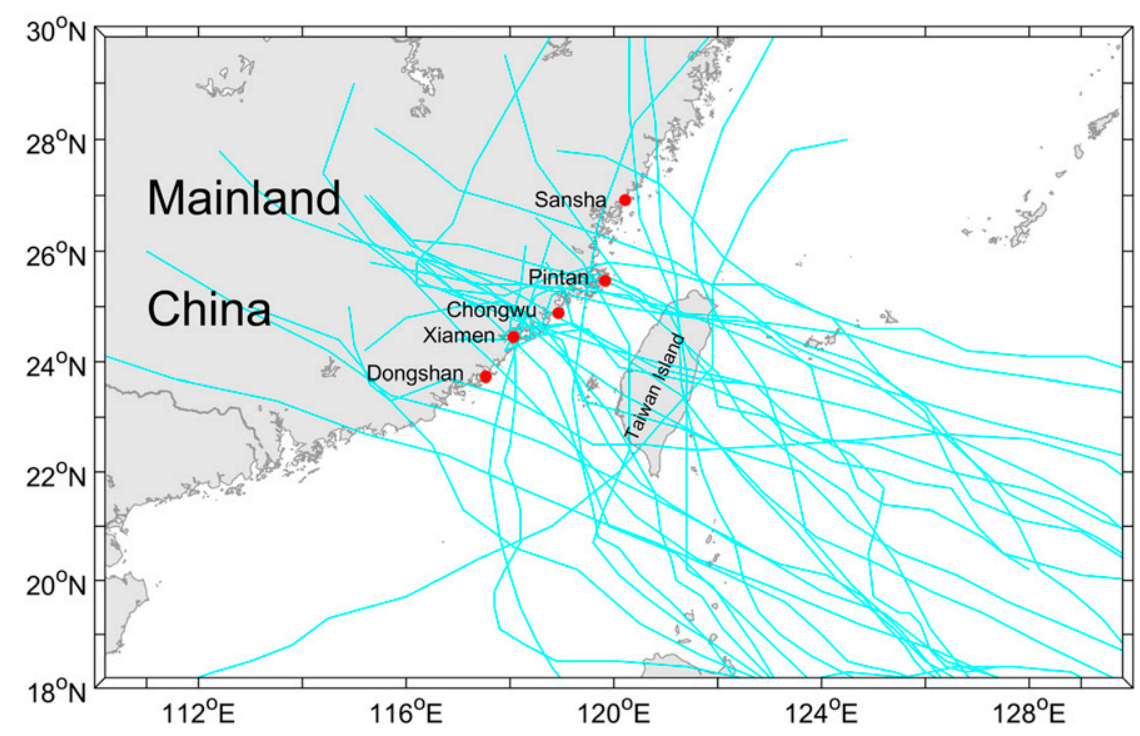

FIG. 4. Best tracks of typhoons that affected the coast of Fujian Province during 1969-2001.

the astronomical tide was calculated separately using a numerical model (D. F. Wang et al. 2010) with assimilation of tidal table data at 63 tide gauges along the coast. The model setup was the same as that of the storm surge model without meteorological driving forces. Differently, the open boundary was forced by tidal elevation that included eight astronomical tide constituents $\left(\mathrm{M}_{2}, \mathrm{~S}_{2}, \mathrm{~N}_{2}, \mathrm{~K}_{2}, \mathrm{~K}_{1}, \mathrm{O}_{1}, \mathrm{P}_{1}\right.$, and $\left.\mathrm{Q}_{1}\right)$ obtained from the NAO99 tidal prediction system. According to historical astronomical tide data, there is at most a 1-m tidal amplitude in $1 \mathrm{~h}$ along the Fujian coast. Thus, the tide surge database contained tide elevation at 195 water points at 15 -min intervals throughout the year. The astronomical tide database, which was also recorded in a netCDF file with size of $30 \mathrm{MB}$, should be calculated annually when tidal table data are published. The total water level is calculated by linear addition of the storm surge onto the astronomical tide.

In this method, the nonlinear interaction between a storm surge and the astronomical tide is considered negligible. Horsburgh and Wilson (2007) suggested that the residual peak in the North Sea of the United Kingdom, which might contain surge, tide-surge interaction, harmonic prediction errors, and phase errors, always avoids high water for any finite tidal phase shift, and that an increasing tidal range appears to reduce the risk of residual peaks arriving near high water. On the basis of an idealized case, Kim et al. (2008) also indicated that surge was increased (decreased) in the low (high) water phase. For two separate typhoon processes, Zhang et al. (2020) showed that the interaction residual led to oscillation within the tidal period along the Fujian coast with an average value of between 15.4 and $4.9 \mathrm{~cm}$, depending on typhoon intensity. Furthermore, the peak (trough) residual value was found to appear at low tide and during the rising tide stage (high tide and during the falling tide stage). Moreover, the tide-surge interaction caused the peak water level to arrive earlier because tidal wave propagation was accelerated owing to the increased water depth attributable to the storm surge. For storm surge warnings, the high tide is of major concern because disasters always occur when a storm surge is superposed on a high tide. Consequently, in comparison with the magnitude of the astronomical tide, it is believed that neglect of the nonlinear interaction is acceptable for early warning of storm surge overflow in the study area.

\section{c. Searching optimization of a numerical scenario database}

Due to a real typhoon track and its parameters are unique, the method of searching optimization is proposed. The method search the most similar typhoon parameters and the accordingly surge from the gridded database using optimized interpolation based on series sensitivity experiments. To evaluate the uncertainty in storm surge forecast sensitivity to changes in forecasted maximum wind speed, forward speed, and track angle, numerical experiments were performed assuming certain percent changes in these input conditions (Xie et al. 2009). The results can be summarized as follows.

1) For a $12.5 \%$ change in maximum wind speed (e.g., change from 45 to $40 \mathrm{~m} \mathrm{~s}^{-1}$ ) at $6 \mathrm{~h}$ before landfall, the peak surge changes obviously by up to $10 \%$. However, the divergence is reduced by $4.4 \%$ when using the average value of the peak surge, calculated using constant central maximum wind speeds with values of 40 and $45 \mathrm{~m} \mathrm{~s}^{-1}$, to replace that of the changing maximum wind speed.

2) For a $25 \%$ change in central forward speed at $12 \mathrm{~h}$ before landfall (e.g., change from 30 or 15 to $20 \mathrm{~km} \mathrm{~h}^{-1}$ ), the peak surge changes by $1.9 \%$.

3) For a $45^{\circ}$ change in track angle at $12 \mathrm{~h}$ before landfall, the peak surge changes by $1.4 \%$.

Consistent with Irish et al. (2008) and Niedoroda et al. (2010), the influence of both forward speed and track angle of a $\mathrm{TC}$ at $12 \mathrm{~h}$ before landfall is assumed small in comparison with other factors. The uncertainty in a surge forecast is most sensitive to the uncertainty in the forecasted maximum wind speed. This is consistent with Irish et al. (2011) who showed 
TABLE 1. Search rules of the five TC parameters.

\begin{tabular}{cll}
\hline \hline $\begin{array}{c}\text { TC } \\
\text { parameters }\end{array}$ & \multicolumn{1}{c}{ Searching values } \\
\hline$W_{\max }$ & $W_{1 \max }, W_{2 \max }\left(25,30,35,40,45,50,55,60,65,70 \mathrm{~m} \mathrm{~s}^{-1}\right)$ & \multicolumn{1}{c}{ Searching rules } \\
$V$ & $V_{1}, V_{2}\left(0.05^{\circ}, 0.15^{\circ}, 0.25^{\circ}, 0.35^{\circ}, 0.45^{\circ} \mathrm{h}^{-1}\right)$ & $W_{1 \max } \leq W_{\max } \leq W_{2 \max }$ \\
$\alpha$ & $\alpha_{1}\left(0^{\circ}, 22.5^{\circ}, 45^{\circ}, 225^{\circ}, 247.5^{\circ}, 270^{\circ}, 292.5^{\circ}, 315^{\circ}, 337.5^{\circ}\right)$ & $V_{1} \leq V \leq V_{2}$ \\
$N, E$ & $N_{1} E_{1}, N_{1} E_{2}, N_{2} E_{1}, N_{2} E_{2}\left(N: 19^{\circ}, 19.1^{\circ}, 19.2^{\circ}, \ldots, 28.5^{\circ} \mathrm{N} ; E: 115^{\circ}, 115.1^{\circ}, 115.2^{\circ}, \ldots, 126^{\circ} \mathrm{E}\right)$ & $\alpha N_{1} \leq N \leq N_{2,} E_{1} \leq E \leq E_{2}$ \\
\hline
\end{tabular}

that surges are most sensitive to central pressure, which, similar to maximum wind speed, reflects TC intensity. It has been demonstrated that these TC parameters, which vary over small ranges at $6-12 \mathrm{~h}$ before landfall, induce acceptably negligible effect on storm surges in comparison with the uncertainty of TC forecasting and storm surge modeling. This provides an important basis for the fast computation method proposed in this paper.

In the cases of 24- and 24-48-h forecasting, 2562 typhoon tracks with different parameters are retrieved from the probability circle. For each typhoon track, the forward speed is calculated according to the beginning and ending locations of the typhoon center. Then, the typhoon location and the maximum wind speed are interpolated linearly at 15-min intervals, i.e., the same interval as in the tide database. Thus, each typhoon track contains $97(=24 \times 4+1)$ combinations of parameters in a time series. Supposing that the storm surge induced by one combination of the parameters of $W_{\max }, V, \alpha$, $N$, and $E$ is calculated as $\zeta\left(W_{\max }, V, \alpha, N, E\right)$, then the process for searching and optimizing the surge data from the database is as follows.

The searching rules of the five parameters, listed in Table 1, are determined by comparing the values to those defined in the storm surge database (as described in section 2b). 1) Two adjacent maximum wind speeds $\left(W_{1 \max }\right.$ and $\left.W_{2 \max }\right)$ are decided according to the interval of the value, e.g., suppose $25<W_{\max }<30 \mathrm{~m} \mathrm{~s}^{-1}$, then $W_{1 \max }=25 \mathrm{~m} \mathrm{~s}^{-1}$ and $W_{2 \max }=30 \mathrm{~m} \mathrm{~s}^{-1}$. 2) Similarly, two adjacent forward speeds $\left(V_{1}\right.$ and $\left.V_{2}\right)$ are decided, e.g., suppose $0.05^{\circ}<V<0.15^{\circ} \mathrm{h}^{-1}$, then $V_{1}=0.05^{\circ} \mathrm{h}^{-1}$ and $V_{2}=0.15^{\circ} \mathrm{h}^{-1}$. 3) A single track angle is determined that is equal to the closest angle in the database, e.g., suppose $11.25^{\circ}<\alpha \leq 33.75^{\circ}$, then $\left.\alpha_{1}=22.5^{\circ} .4\right)$ Four typhoon locations $\left(E_{1}, N_{1} ; E_{2}, N_{2} ; E_{3}, N_{3}\right.$; and $\left.E_{4}, N_{4}\right)$ are decided according to the spatial position, e.g., suppose $E=119.25^{\circ}$ and $N=24.58^{\circ}$, then $E_{1}=119.2^{\circ}$ and $N_{1}=$ $24.5^{\circ}, E_{2}=119.2^{\circ}$ and $N_{2}=24.6^{\circ}, E_{3}=119.3^{\circ}$ and $N_{3}=24.5^{\circ}$, and $E_{4}=119.3^{\circ}$ and $N_{4}=24.6^{\circ}$.

On the basis of the above, there are 16 combinations of typhoon parameters, i.e., two maximum wind speeds plus two forward speeds, one track angle, and four locations. Therefore, 16 separate storm surges can be searched from the database and used to calculate $\zeta\left(W_{\max }, V, \alpha, N, E\right)$, as shown in Fig. 5 . First, the 16 surges $\left(\zeta_{1}, \ldots, \zeta_{16}\right)$ are divided into four groups with different parameters $\left(W_{\max }, V, \alpha\right)$ at four positions $\left(E_{1} / E_{2}\right.$, $\left.N_{1} / N_{2}\right)$. On the basis of the above four group surges, four surges $\left(\delta_{1}, \ldots, \delta_{4}\right)$ at the target location $(E, N)$ with four combinations of typhoon parameters $\left(W_{1 \max } / W_{2 \max }, V_{1} / V_{2}, \alpha_{1}, N, E\right)$ are calculated using inverse distance weighting. Then, two surges $\left(\varepsilon_{1}\right.$ and $\varepsilon_{2}$ ) with parameters $W_{\max }, V_{1} / V_{2}, \alpha_{1}, N$, and $E$ are calculated using the weighted mean of the value of $\delta_{1} / \delta_{2}$ and $\delta_{3} / \delta_{4}$ according to the values of $W_{\max }, W_{1 \max }$, and $W_{2 \max }$. Finally, the values of $\varepsilon_{1}$ and $\varepsilon_{2}$ are interpolated linearly according to the values of $V, V_{1}$, and $V_{2}$ to determine a single surge $\zeta$ with the parameters $W_{\max }, V, \alpha_{1}, N$, and $E$. Thus, the storm surge $\zeta\left(W_{\max }, V, \alpha, N, E\right)$ is determined as being equal to $\zeta$.

The surges associated with the other 96 combinations of typhoon parameters for one typhoon track are computed in the same way as above. Therefore, a surge curve can be drawn based on the single time series of storm surge values at 15 -min intervals for the 24- and 24-48-h forecast time produced for each water point. Similarly, 2562 curves are achieved corresponding to the perturbed typhoons. The astronomical tide at 15-min intervals during the typhoon forecast time is searched from the tide database, and there is only one tide curve for a particular time at a certain water point. Ultimately, the total water level is determined by summation of the storm surge and the tide level. Thus, 2562 total water level curves are produced for each coastal water point. The ensemble of surges for each water point can be used to provide forecasters with early warning products, e.g., tide gauge warnings and warnings of seawall overflow.

\section{Case study of application of the method in Fujian Province, China}

Fujian Province (China), on the western side of the Taiwan Strait, is located at the western edge of the Northwest Pacific, which is a region of frequent TC formation. Typhoons often induce storm surges and coastal floods in this area that cause major property damage and loss of life. For example, in 1999, Typhoon Dan caused damage estimated at $\$ 0.61$ billion and 72 fatalities. During 1949-90, 69 typhoons generated storm surges along the coast of Fujian Province that were $>1 \mathrm{~m}$; of these, four storm surges were $>2 \mathrm{~m}$ (Yang et al. 1993). According to Feng et al. (2018), the duration of the storm surges over $1 \mathrm{~m}$ had an increasing trend along the northern coast of Fujian Province during 1997-2016. Therefore, this study considered Fujian Province as an example case for application of the proposed method to provide rapid ensemble predictions of storm surges for operational and early decision-making.

A surge overflow of seawall warning system (SOSWWS) was established for the coast of Fujian Province based on GIS to help provide a rapid overview of the risk of coastal disaster. The system could be installed on any commonly available PC. Incorporated in the system are the analyzed TC track in real time and the forecasted tracks from five operational weather 


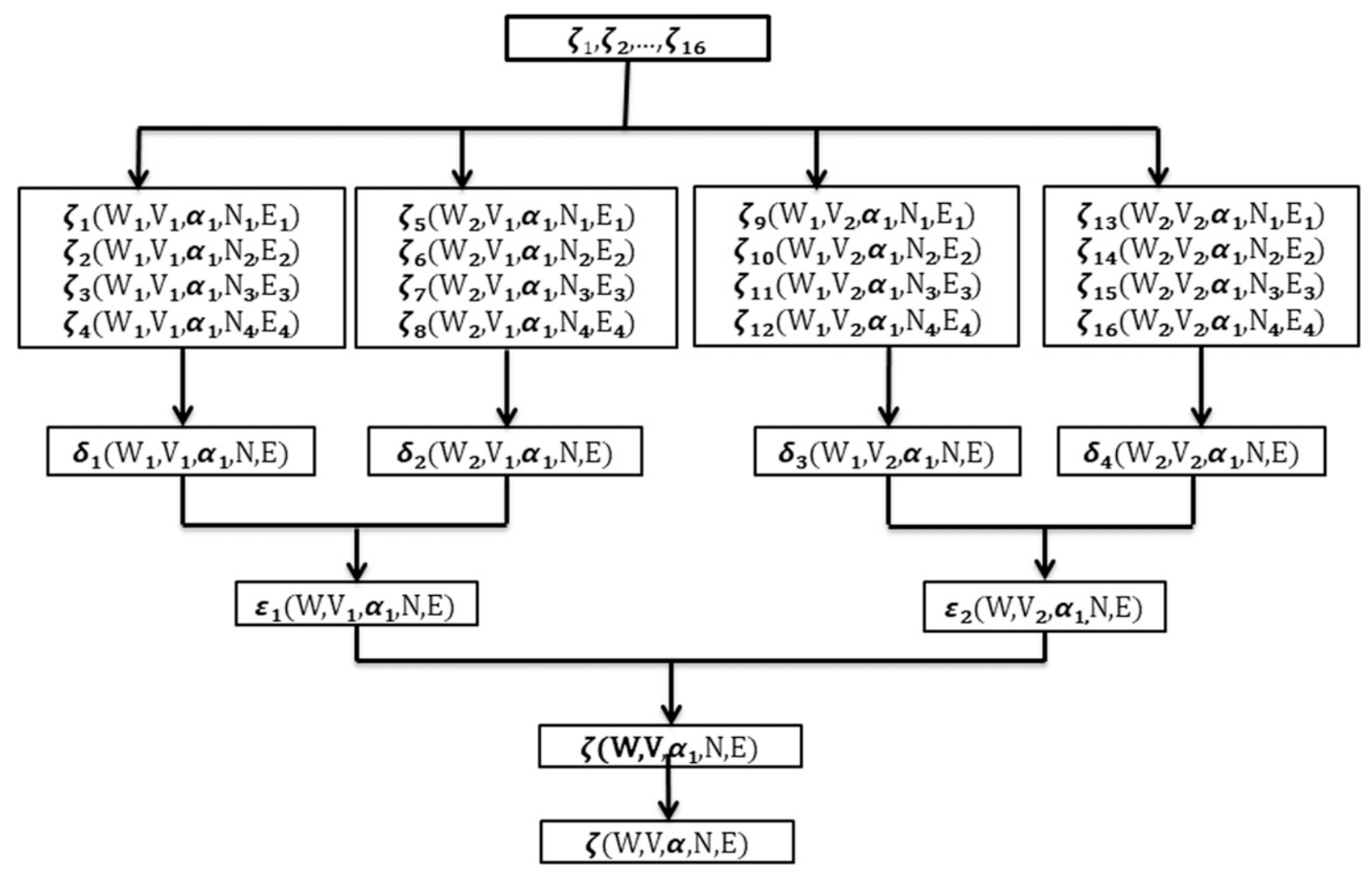

FIG. 5. Flowchart of storm surge computation method based on surge database. $W, V, \alpha, N$, and $E$ represent the wind speed, typhoon forward speed, track angle, latitude, and longitude of the TC central position, respectively; $\zeta, \delta$, and $\varepsilon$ represent the storm surge for typhoon parameters $W, V, \alpha, N$, and $E$.

forecast centers: the CMA, the JMA, Joint Typhoon Warning Center of the United States, the Taiwan Meteorological Center, and the Hong Kong Meteorological Center. Generally, the interval of the analyzed data from the CMA is $6 \mathrm{~h}$, which is reduced to $3 \mathrm{~h}$ when a typhoon is inside the 48 - $\mathrm{h}$ warning line. The forecasted data of typhoon tracks for the coming 24 and $48 \mathrm{~h}$ are usually released every $6 \mathrm{~h}$, i.e., at 0200,0800 , 1400 , and 2000 Beijing time (BT; BT $=\mathrm{UTC}+8 \mathrm{~h}$ ) every day. When forecasting a single storm surge event, a user could select data from one forecast center or self-set the forecast information including TC location and intensity at 24- and 48-h lead times. Approximately 1-2 min after clicking the calculation button, the ensemble forecasting results for the seawalls/gauge stations are retrieved, and those stations are listed when triggering alert levels. For example, Fig. 6 shows a 48 -h time series of the 2562 prediction results of the total water level for a seawall, with different tracks highlighted in different colors (i.e., orange for current track, rose red for right tracks, and crimson for left tracks), together with a blue curve that represents the astronomical tide. The four alert levels in different colors (i.e., red, orange, yellow, and blue) are shown in the graph for comparison with the ensemble prediction results. It can be seen that there are large differences not only in the predicted magnitude, which reach up to $1-2 \mathrm{~m}$, but also in its timing. Such a wide range of outcomes is important for governmental decision-making regarding protection measures; however, at this location, the ensemble predicts almost zero risk of the alert level being exceeded. Moreover, seawalls where the water level is higher than the alert level would be represented in highlighted colors in the map, and also listed in a table together with the probability of occurrence and the duration. The probability of the water level exceeding alert level $P$ is calculated as follows:

$$
P=\frac{\sum_{i=1}^{T_{c}} W_{i}}{T_{c}} \times 100 \%,
$$

where $T_{c}$ is the total number of generated forecast tracks, and $W_{i}$ is equal to 1 when the $i$ th prediction water level exceeds the alert level; otherwise, $W_{i}$ is equal to 0 . By taking the maximum value of the 2562 forecasted results at each forecasting time, the time series of the most dangerous envelope (forecast) can be obtained.

\section{Analysis of storm surge ensemble prediction results for Typhoon Soudelor (1513) and Typhoon Maria (1808)}

\section{a. Descriptions of typhoons and data}

Taking the forecasted storm surge results of both Typhoon Soudelor (1513) with reasonably nonlinear tracks and Typhoon 


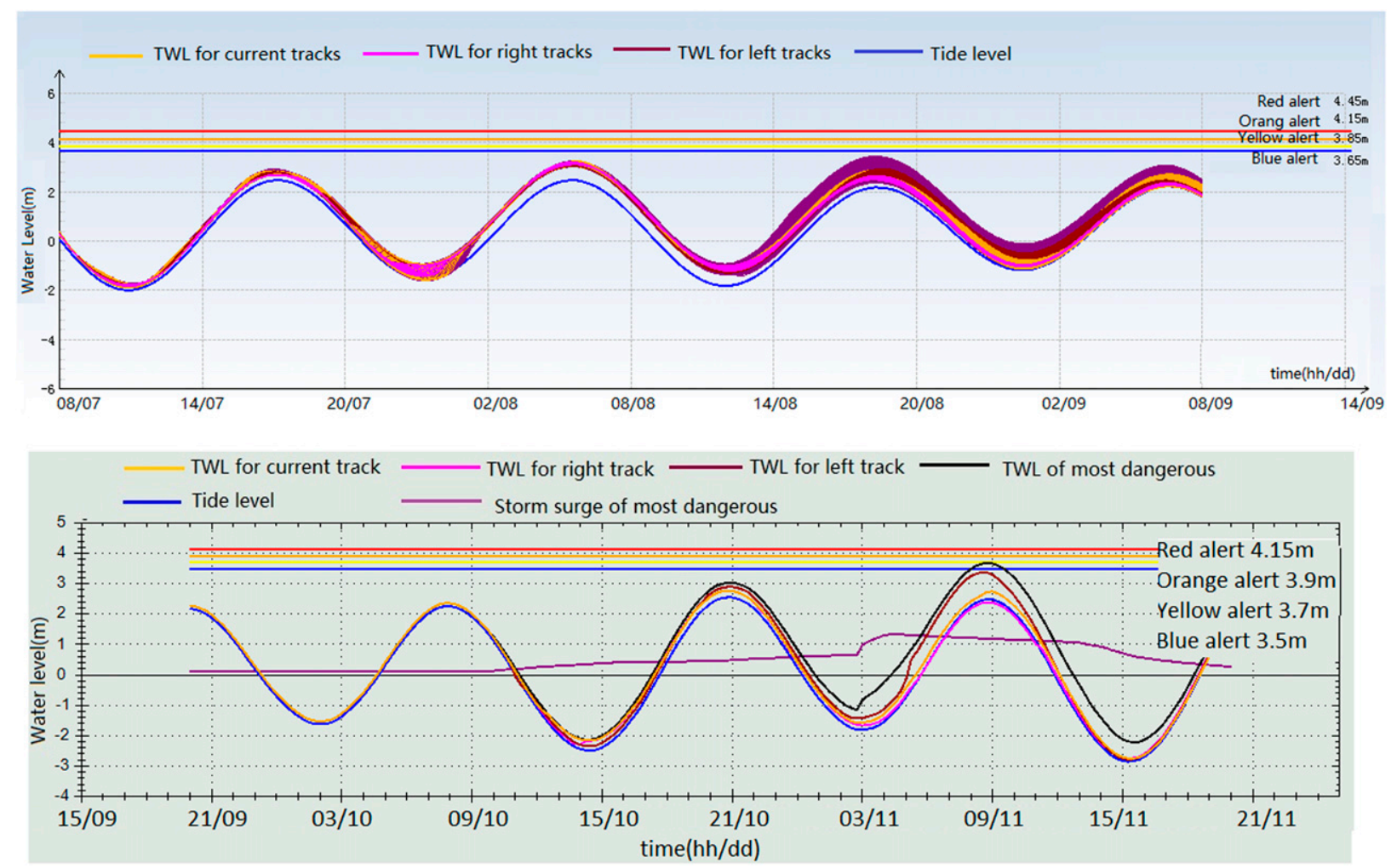

FIG. 6. Storm surge ensemble prediction results for a seawall with (top) all ensemble members and (bottom) partial members.

Maria (1808) with large time prediction errors as examples, the practicability and effectiveness of the method of fast ensemble prediction using SONSD were assessed.

The best track for each of the two typhoons, shown in Fig. 7, was obtained from the CMA website. Typhoon Soudelor was generated over the northwest Pacific at around 0200 BT 2 August 2015, with maximum wind speed of $28 \mathrm{~m} \mathrm{~s}^{-1}$ and minimum central pressure of $982 \mathrm{hPa}$. Soudelor subsequently moved toward the northwest and strengthened gradually. Landfall was made first at Hualian on the island of Taiwan at around 0440 BT 8 August, following which Soudelor then moved southeastward. On entering the Taiwan Strait at around $1100 \mathrm{BT}$, it then turned to move north by northwest. It subsequently made landfall at Putian in Fujian Province at 2210 BT 8 August 2015, with maximum wind speed of $38 \mathrm{~m} \mathrm{~s}^{-1}$ and minimum central pressure of $970 \mathrm{hPa}$.

Typhoon Maria was generated over the ocean east of Guam at 2000 BT 4 July 2018. Maria strengthened rapidly to a super typhoon with maximum wind speed of $60 \mathrm{~m} \mathrm{~s}^{-1}$ and minimum central air pressure of $925 \mathrm{hPa}$ at $0800 \mathrm{BT} 8 \mathrm{July}$. It then moved northwestward at the speed of $5-10 \mathrm{~km} \mathrm{~h}^{-1}$ and made landfall on the Huangqi Peninsula in Lianjiang (Fujian Province) at 0910 BT 11 July, with maximum wind speed of $42 \mathrm{~m} \mathrm{~s}^{-1}$ and minimum central pressure of $960 \mathrm{hPa}$. Maria was the strongest typhoon to make landfall in Fujian in July since records began.

Using the SOSWWS to track the forecasted storm surge induced by Soudelor and Maria, separate ensemble surge forecasts were generated based on the typhoon forecasts issued by the CMA approximately $48 \mathrm{~h}$ prior to landfall. Only the prediction results for the high water level (HWL) are assessed because surge disasters are caused most often by superposition of the storm surge on the high tide level. Predicted HWLs at five tide gauges, based on the current typhoon track and the ensemble (i.e., most dangerous) forecast were extracted for comparison with hourly data measured in situ, provided by Fujian Marine Forecasts. Prediction deviation $\left(d_{i}\right)$, as shown in Eq. (3), and the mean error (ME) or "bias", [Eq. (4)] were calculated to assess the difference between predictions and observations. As a widely used statistical indicator, the MAE [Eq. (5)] was also determined to assess the magnitude of the prediction error at the five tide gauges, and the RMSE [Eq. (6)] was calculated to assess the dispersion of the prediction error:

$$
\begin{aligned}
d_{i} & =\varsigma_{i}-\widehat{\varsigma}_{i}, \\
\mathrm{ME} & =\frac{1}{N} \sum_{i=1}^{N} d_{i}, \\
\mathrm{MAE} & =\frac{1}{N} \sum_{i=1}^{N}\left|d_{i}\right|, \\
\mathrm{RMSE} & =\sqrt{\frac{1}{N} \sum_{i=1}^{N} d_{i}^{2}},
\end{aligned}
$$




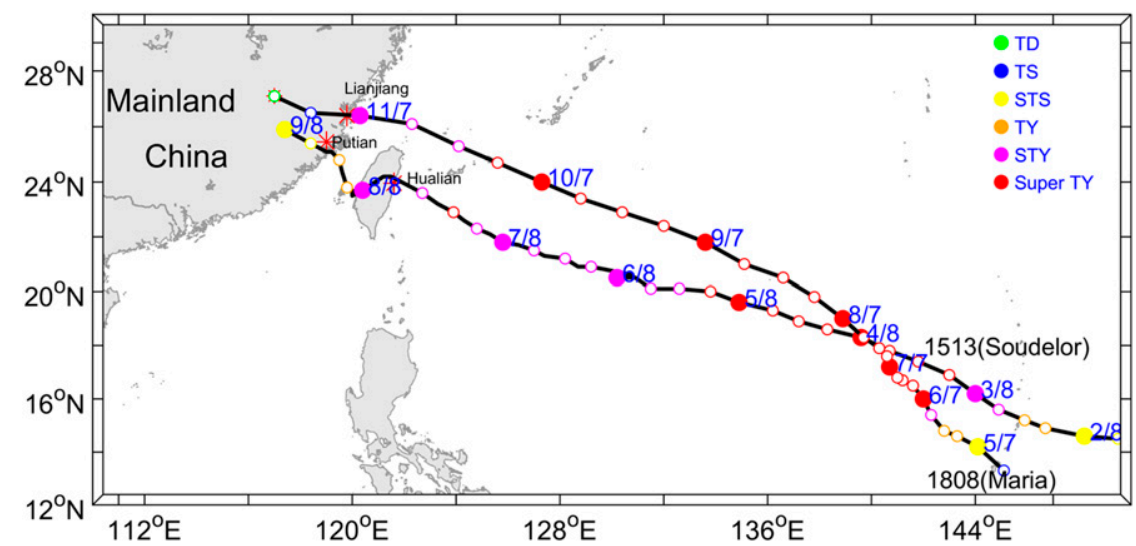

FIG. 7. Best tracks for Typhoon Soudelor and Typhoon Maria. Solid dots represent 0800 BT on date (day/month) and hollow dots represent the TC central position every $6 \mathrm{~h}$; different colors represent TC intensity according to the National Standard for Tropical Cyclone Classification (classified based on maximum wind speed with reference to GB/T 19201-2006; TD: tropical depression, $10.8-17.1 \mathrm{~m} \mathrm{~s}^{-1}$; TS: tropical storm, 17.2-24.4 $\mathrm{m} \mathrm{s}^{-1}$; STS: severe tropical storm, 24.5-32.6 $\mathrm{m} \mathrm{s}^{-1}$; TY: typhoon, 32.7-41.4 $\mathrm{m} \mathrm{s}^{-1}$; STY: severe tropical typhoon, $41.5-50.9 \mathrm{~m} \mathrm{~s}^{-1}$; and Super TY: super typhoon, $\geq 51.0 \mathrm{~m} \mathrm{~s}^{-1}$ ).

where $s_{i}$ and $\widehat{\varsigma}_{i}$ represent the prediction and observation, respectively, and parameter $N$ represents the total number of matched observations.

\section{b. Performance of storm surge prediction for Typhoon Soudelor}

A schematic of the ensemble perturbed forecasted tracks for Typhoon Soudelor at approximately $48 \mathrm{~h}$ prior to landfall from 0800 BT 7 August 2015 is shown in Fig. 8, with forecasted maximum wind speeds of $42 \mathrm{~m} \mathrm{~s}^{-1}$ at $24-\mathrm{h}$ and $23 \mathrm{~m} \mathrm{~s}^{-1}$ at 48 -h forecast times. The results for three predicted and observed HWLs at five gauge stations are presented in Fig. 9 for the purpose of comparison. The deviations, biases, MAEs, and RMSEs between the predicted values and the observations are listed in Table 2. The results show that the predicted HWLs from both the forecasted current track and the ensemble tracks fit well with the observations at the time of the first HWL (Fig. 9a), with MAE/RMSE values of 14.6/16.4 and $12.6 / 17.6 \mathrm{~cm}$, respectively. For the second $\mathrm{HWL}$, the prediction error of the forecasted current track is larger than that of the ensemble tracks, reaching a maximum deviation of $-40 \mathrm{~cm}$ and a maximum ME of $-16.8 \mathrm{~cm}$, with MAE/RMSE of $24.0 / 26.6 \mathrm{~cm}$. Conversely, the negative bias of the ensemble prediction is reduced to $-0.4 \mathrm{~cm}$, the maximum deviation is $-10 \mathrm{~cm}$, and the MAE/RMSE is reduced to $9.6 / 12.2 \mathrm{~cm}$. The prediction of the forecasted current track at the time of the third HWL is close to the observation, with the smallest negative bias of $-2.6 \mathrm{~cm}$ and MAE/RMSE of $7.0 / 7.8 \mathrm{~cm}$. However, the deviation of the ensemble prediction is much larger, e.g., positive deviation of 68 and $64 \mathrm{~cm}$ at Chongwu gauge and Xiamen gauge, respectively, and with an average positive bias of $37.2 \mathrm{~cm}$ for the five gauges. Moreover, the MAE is increased to $37.2 \mathrm{~cm}$ with RMSE of $44.9 \mathrm{~cm}$ owing to the overestimation at two gauges i.e., Chongwu gauge and Xiamen gauge. Overall, the prediction performance for the first, second, and third times of HWL is satisfactory, with MAE/RMSE of $0.16 / 0.21,0.15 / 0.20$, and $0.36 / 0.40 \mathrm{~h}$, respectively.

These results can be analyzed and summarized as follows:

1) The prediction result for HWL time reflects satisfactory assimilation of the harmonic tide used for tidal prediction with mean MAE/RMSE of $0.22 / 2.27 \mathrm{~h}$.

2) At the time of the first HWL, which is close to the forecast beginning time, the actual typhoon position is located around dot "A" in Fig. 8, because the exact times of the HWL at the five gauges are $1-2 \mathrm{~h}$ apart. All the ensemble forecasted positions including the forecasted current position are close to the actual position, indicating reasonable agreement between the predictions and the observation. The result shows that SONSD allows rapid surge calculation while guaranteeing accuracy.

3) At the time of the second HWL, the actual typhoon position, which is located around dot " $\mathrm{B}$ " in Fig. 8, is far from the forecasted current position. The forecasted current track deviates from the actual typhoon track, while the ensemble forecasted tracks including the right track (e.g., path "AB") do cover the actual track. Therefore, the predicted value of the right track, which is contained within the ensemble computation results, is reasonably consistent with the observations, demonstrating marked improvement of the storm surge forecast by the introduction of the ensemble prediction.

4) At the time of the third HWL, the actual typhoon position is located around dot "C" in Fig. 8, close to the forecasted current typhoon position. Although the track angles are noticeably different to both the actual track of around $75^{\circ}$ and the forecasted current track of near $45^{\circ}$, the predicted HWLs fit reasonably well with the observations. The result shows that the predicted storm surge is much more sensitive to variation of the typhoon's central position than 


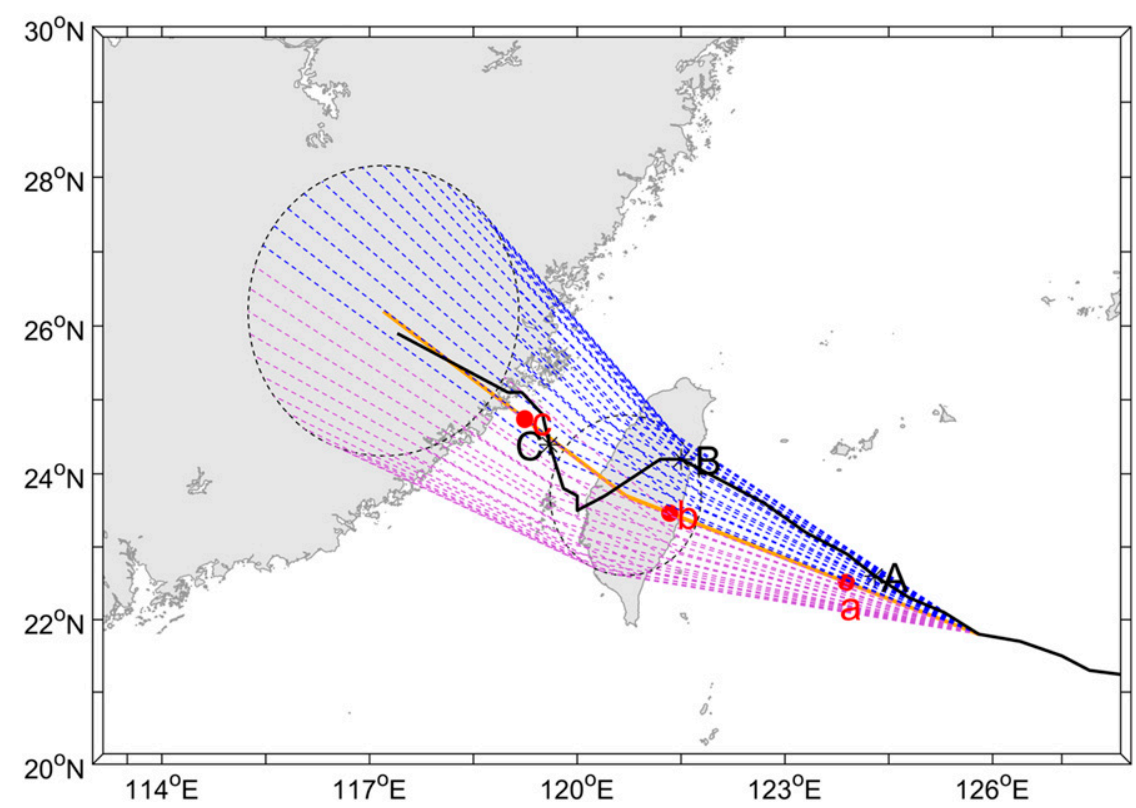

FIG. 8. Schematic showing 48-h forecast tracks from 0800 BT 7 Aug 2015 for Typhoon Soudelor. The black line is the actual track, the orange line is the forecasted current track, and the other lines are ensemble tracks. Dots A, B, and C represent the real TC positions at around the times of the first, second, and third HWL at the five tide gauges, respectively. Dots a, b, and $\mathrm{c}$ represent the forecasted current TC positions at around the times of the first, second, and third HWL, respectively.

to variation of the direction of typhoon movement. This finding is consistent with the results of previous research by Xie et al. (2009) and others (Irish et al. 2008; Niedoroda et al. 2010). Although several typhoon center positions forecasted by the ensemble around the current position are close to the actual position, most are far away, leading to large deviation in the ensemble predictions of HWL when directly using the most dangerous surge. Especially at the locations of the Chongwu and Xiamen gauges, which are within the radius of maximum wind speed and close to the typhoon track, the predicted storm surge is approximately 144 and $125 \mathrm{~cm}$ (determined as the HWL minus the tide), respectively. This could represent possibly the most dangerous situation presented to the user. Similarly, JMA issued a storm surge distribution map based on the maxima among all scenarios (i.e., the worst storm surge values) for the forecast time (Hasegawa et al. 2017). The maximum map supports risk management by clarifying worst-case scenarios, although the information is approximate and such scenarios may not arise. In addition, an experienced forecaster could determine whether the situation would be likely to occur given the pertaining meteorological conditions, which would help regarding the issuance of advance warnings.

\section{c. Performance of storm surge prediction for Typhoon Maria}

A schematic of the ensemble perturbed forecasted tracks for Typhoon Maria at approximately $48 \mathrm{~h}$ prior to landfall from 2000 BT 9 July 2018 is shown in Fig. 10, with forecasted maximum wind speeds of $52 \mathrm{~m} \mathrm{~s}^{-1}$ at $24 \mathrm{~h}$ and $30 \mathrm{~m} \mathrm{~s}^{-1}$ at $48 \mathrm{~h}$. The results for three predicted and observed HWLs at the five gauge stations are presented in Fig. 11 for the purpose of comparison. The results show that the predictions of the ensemble forecasted tracks match the observations much better than those of the single current track at all three HWL times. The deviation values listed in Table 3 show that the predictions of the forecasted current track are obviously underestimated, reaching a large negative deviation of $>-50 \mathrm{~cm}$ at several gauges with negative biases of $-27.8,-23.2$, and $-58.5 \mathrm{~cm}$ at the first-third HWL times, respectively. In contrast, the ensemble prediction has smaller or positive bias with $\mathrm{ME}$ of $-10.4,7.8$, and $-5.2 \mathrm{~cm}$ at the first-third HWL times, respectively. Moreover, the MAE/RMSE values of the ensemble prediction are encouraging, i.e., reduced from 27.8/30.8, $23.2 / 25.0$, and $58.5 / 58.7 \mathrm{~cm}$ for the current track forecast to $12.8 / 14.2,8.2 / 9.9$, and $24.8 / 28.4 \mathrm{~cm}$ at the first-third HWL times, respectively. Additionally, the prediction performance for the first-third HWL times is also satisfactory, with MAE/RMSE values of $0.24 / 0.34,0.15 / 0.27$, and $0.42 / 0.43 \mathrm{~h}$, respectively.

These results can be summarized as follows:

1) The performance of the prediction for HWL time is satisfactory with mean MAE/RMSE of $0.27 / 0.35 \mathrm{~h}$.

2) At the times of the three HWLs, the actual typhoon positions are located around " $\mathrm{A} / \mathrm{B} / \mathrm{C}$ " and the forecasted current positions are located around " $\mathrm{a} / \mathrm{b} / \mathrm{c}$ " (as shown in Fig. 10). It is evident that the forecasted current track is close to the actual track. However, the forecasted current position is much further away from the coast in comparison 

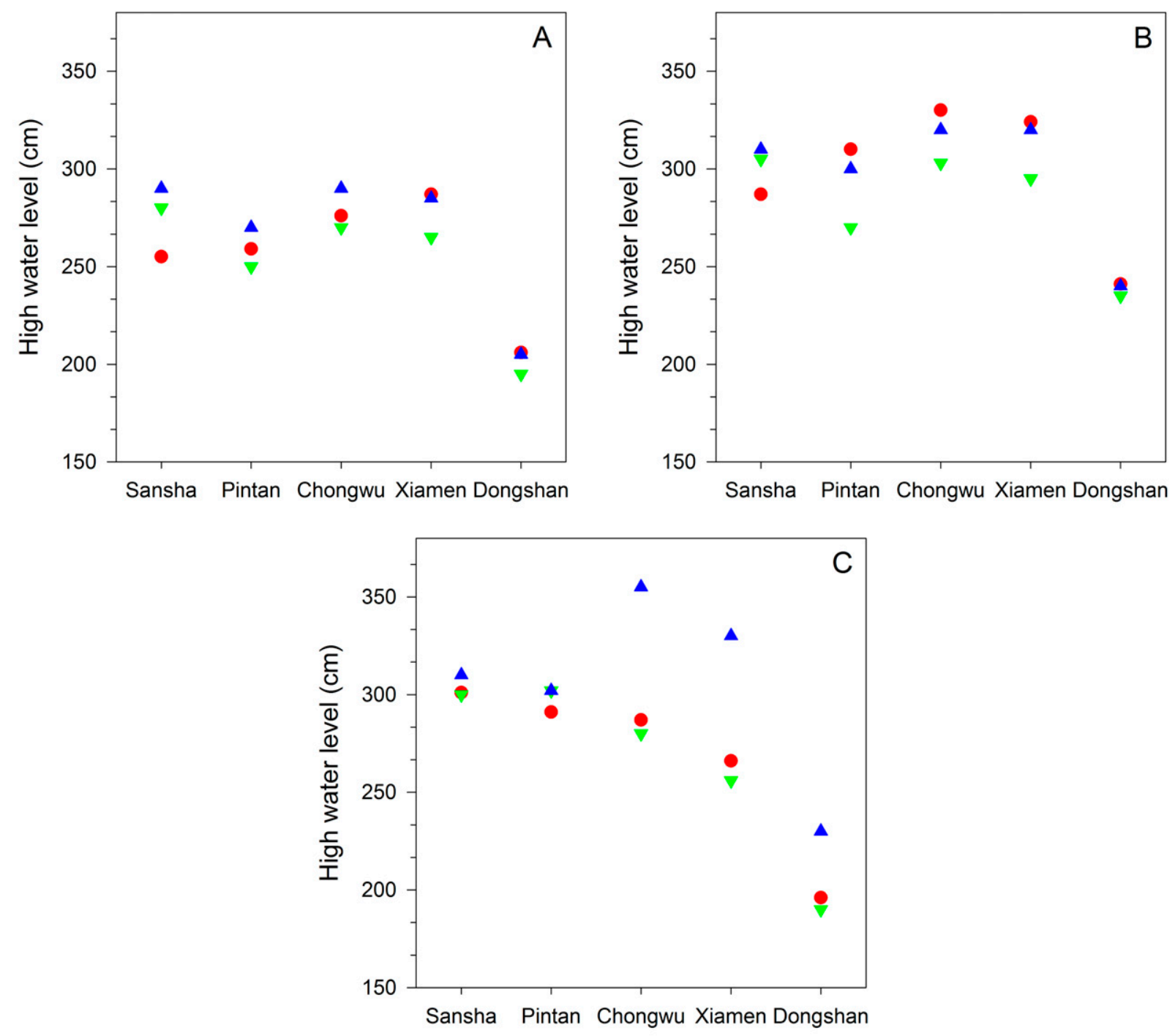

\section{- Observation} $\nabla \quad$ Prediction of current track

Prediction of ensemble tracks

FIG. 9. Predicted and observed high water levels at five gauge stations for Typhoon Soudelor. (a)-(c) Results at the times of the first, second, and third HWL, respectively.

with the actual position owing to the slow forecasted forward speed. Therefore, the predicted HWLs of the current track are underestimated at almost all gauges. Conversely, the actual position is contained within the probability circle; thus, the ensemble predictions of the HWLs are in reasonable agreement with the observations. This helps avoid missed information and demonstrates the marked improvement in storm surge forecasting resulting from the introduction of the ensemble prediction.

\section{Discussion}

The results of the application of the proposed method to Typhoon Soudelor and Typhoon Maria using the SOSWSS showed that the approach of the fast ensemble forecast using SONSD is both feasible and effective. There are three principal advantages to using this approach.

\section{a. The high temporally efficient storm surge ensemble prediction system}

The SOSWWS established based on the SONSD method is easy to operate and highly temporally efficient, which is the most advantage compared with other existing ensemble prediction approaches. It does not require preparation of any documents for prediction events. Hence, interpretation of the prediction results is largely possible without need for professional input. It was shown that each prediction could be generated within only 1-2 min, including gathering typhoon 
TABLE 2. Error statistics of the predicted HWLs compared with observations at tide gauges for Typhoon Soudelor. The terms " $d_{\text {cur }}$ " and " $d_{\text {ens }}$ " represent the prediction deviation of the current forecasted track and of the ensemble forecasted tracks, respectively. "HWL" is the high water level, which represents the superposition of the storm surge on the tide at the time of the predicted HWL.

\begin{tabular}{|c|c|c|c|c|c|c|c|}
\hline & & \multicolumn{2}{|c|}{ First HWL } & \multicolumn{2}{|c|}{ Second HWL } & \multicolumn{2}{|c|}{ Third HWL } \\
\hline \multicolumn{2}{|c|}{ Gauge parameter } & $d_{\text {cur }}$ & $d_{\mathrm{ens}}$ & $d_{\text {cur }}$ & $d_{\mathrm{ens}}$ & $d_{\text {cur }}$ & $d_{\mathrm{ens}}$ \\
\hline Sansha & HWL $(\mathrm{cm})$ & 25 & 35 & 18 & 23 & -1 & 9 \\
\hline & Time (h) & \multicolumn{2}{|c|}{-0.08} & \multicolumn{2}{|c|}{0.08} & \multicolumn{2}{|c|}{0.43} \\
\hline \multirow{2}{*}{ Pintan } & HWL $(\mathrm{cm})$ & -9 & 11 & -40 & -10 & 11 & 11 \\
\hline & Time (h) & & & \multicolumn{2}{|c|}{-0.10} & \multicolumn{2}{|c|}{0.42} \\
\hline \multirow[t]{2}{*}{ Chongwu } & HWL $(\mathrm{cm})$ & -6 & 14 & \multirow{2}{*}{\multicolumn{2}{|c|}{0.00}} & -7 & 68 \\
\hline & Time (h) & & & & & \multicolumn{2}{|c|}{0.60} \\
\hline \multirow[t]{2}{*}{ Xiamen } & HWL $(\mathrm{cm})$ & -22 & -2 & -29 & -4 & -10 & 64 \\
\hline & Time (h) & & & \multicolumn{2}{|c|}{0.20} & \multicolumn{2}{|c|}{0.08} \\
\hline \multirow[t]{2}{*}{ Dongshan } & $\operatorname{HWL}(\mathrm{cm})$ & -11 & -1 & -6 & -1 & -6 & 34 \\
\hline & Time (h) & & & \multicolumn{2}{|c|}{0.38} & \multicolumn{2}{|c|}{0.25} \\
\hline $\mathrm{ME}$ & HWL $(\mathrm{cm})$ & -4.6 & 11.4 & -16.8 & -0.4 & -2.6 & 37.2 \\
\hline \multirow{2}{*}{ MAE/RMSE } & HWL $(\mathrm{cm})$ & $14.6 / 16.4$ & $12.6 / 17.5$ & $24.0 / 26.6$ & $9.6 / 12.2$ & 7.0/7.8 & $37.2 / 44.9$ \\
\hline & Time (h) & \multicolumn{2}{|c|}{$0.16 / 0.21$} & \multicolumn{2}{|c|}{$0.15 / 0.20$} & \multicolumn{2}{|c|}{$0.36 / 0.40$} \\
\hline
\end{tabular}

information, computation and warning visualization, using a commonly available PC when given available typhoon forecast information, which could be obtained automatically from the Internet. In contrast, if the ensemble storm surge prediction were processed in parallel using a physics-based model for each TC member, as in the case of Ding et al. (2016), the procedure would take at least 10 min using approximately 2600 computers/CPUs. In comparison with the overall time of 69 min required to produce a real-time early warning of storm surge using the process of Suh et al. (2015) and 60-90 min for NHC advisories, the performance of the SONSD approach demonstrates high temporal efficiency. Owing to the rapid processing time, a forecaster could also customize the forecast location and maximum wind speed regarding TC intensity forecast uncertainty (Cangialosi 2019; JMA 2019). Overall, the proposed method, which is simple and efficient with respect to its operational application, is rapid in its response to the emergency consultation need and could provide prompt auxiliary decision-making support.

\section{b. The accuracy validation of the searching optimization}

The proposed method SONSD is the key to compute multiply ensemble surges within such short periods. To examine the performance of the SONSD, we verified the searching accuracy by comparing predicted values with numerical model as well as observed ones. First, hourly storm surge predictions were compared with numerical model at 90 seawall locations along Fujian coast. The predictions and numerical simulations were both generated by forecasted current track. The mean MAE and RMSE values of the storm surges during the two TC processes between the numerical model and the SONSD approach, as shown in Fig. 12, are 7.1 and $10.7 \mathrm{~cm}$, respectively, with a correlation coefficient $[R$ in Eq. (7)] of $>0.9$ :

$$
R=\frac{\sum_{i=1}^{N}\left(\varsigma_{i}-\overline{\boldsymbol{s}}_{i}\right)\left(\widehat{\boldsymbol{\varsigma}}_{i}-\overline{\widehat{\boldsymbol{\varsigma}}}_{i}\right)}{\sqrt{\left[\sum_{i=1}^{N}\left(\boldsymbol{\varsigma}_{i}-\overline{\boldsymbol{s}}_{i}\right)^{2}\right]\left[\sum_{i=1}^{N}\left(\widehat{\boldsymbol{s}}_{i}-\overline{\widehat{\varsigma}}\right)^{2}\right]}} .
$$

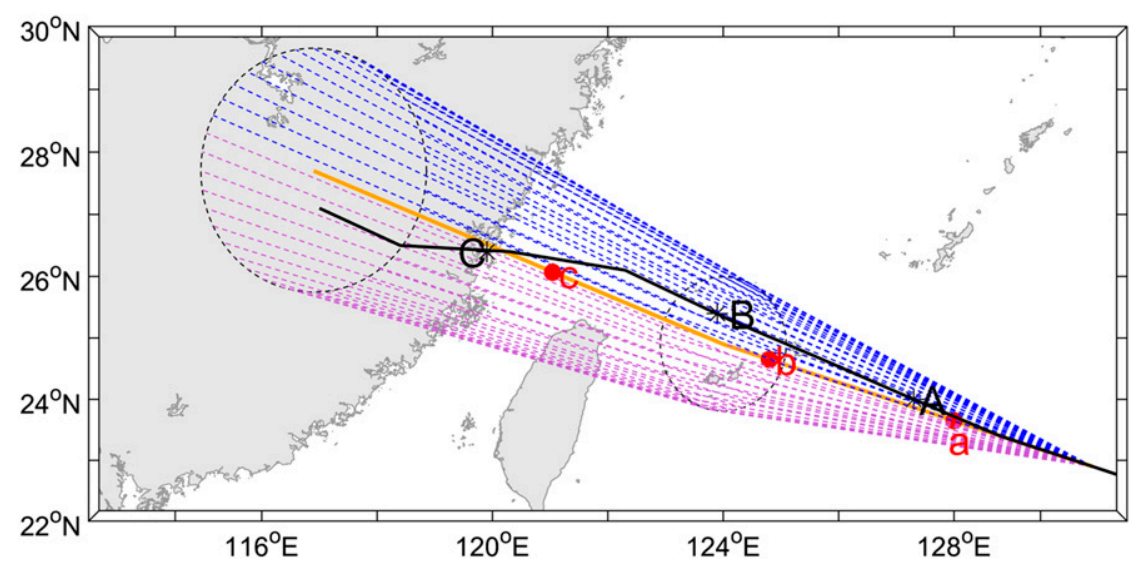

FIG. 10. As in Fig. 8, but for Typhoon Maria. 

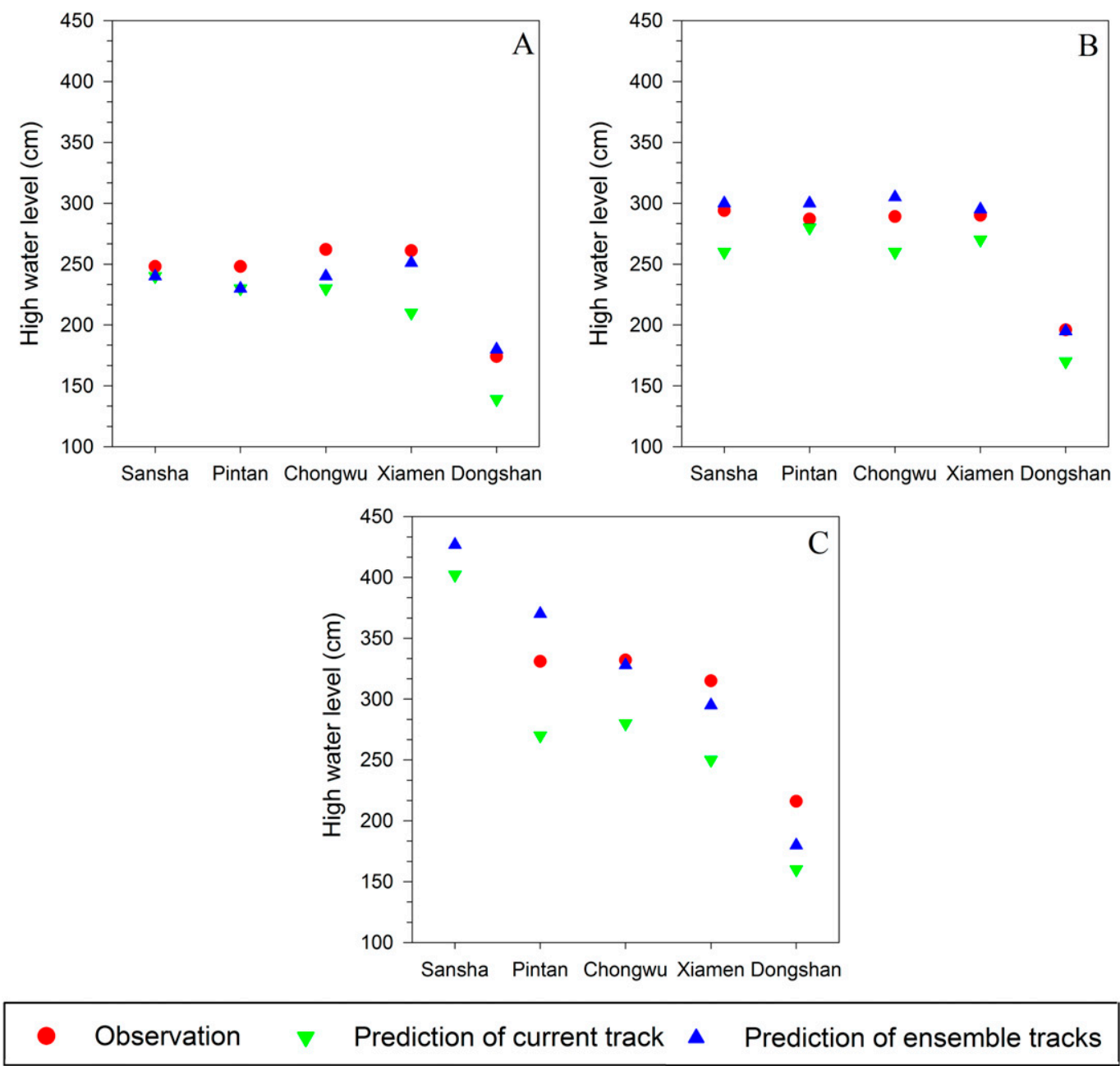

FIG. 11. As in Fig. 9, but for Typhoon Maria.

The result indicated that under the condition of an accurate TC forecast, the accuracy of the predicted water level is equivalent to that of a physics-based numerical model, while the need for real-time simulation is avoided. Besides, hourly storm surge predictions at Xiamen tide station were further compared with observations during historical 25 typhoons. The MAE and RMSE values, as shown in Fig. 13, are 19.2 and $24.2 \mathrm{~cm}$, respectively, with $R$ of 0.59 . The predictions were calculated from SOSWWS generated by linear track at a 24 -h interval. It suggested that the errors due to SONSD are comparable to the numerical model. Both the hindcast errors are comparable to the accuracy of those models used in operational prediction systems (Hasegawa et al. 2012; Forbes et al. 2014; Suh et al. 2015). The SONSD is accurate and effective because the database was calculated using a wellcalibrated numerical model of the study area. Thus, the accuracy of the SONSD is based on the numerical model which was used to calculate the scenario storm surge database.

Additionally, as described in section $2 \mathrm{~b}$, the astronomical tide data were calculated using a well-calibrated astronomical tide model that assimilated harmonic analysis data at the coastal gauge stations, which could be difficult to incorporate in a surge-tide coupled model. The mean RMSE and MAE values between the time series of the harmonic analysis tide and the SONSD tide, as shown in Fig. 14, are 11.6 and $9.7 \mathrm{~cm}$, respectively, with a mean value of $R$ of $>0.99$. Moreover, the phase of the forecasted HWL searched from the database is reasonably accurate with MAE/RMSE of $0.25 / 0.31 \mathrm{~h}$ for all three HWLs during the two TC processes. Consequently, the total water level is reasonably accurate because it represents the direct linear superposition of the storm surge and the astronomical tide level determined by fast calculation using the database (MAE/RMSE of 10.8/12.1 cm versus observations for the first and third HWL predictions of TC Soudelor).

Therefore, several aspects including the accuracy of both the numerical storm surge model and the astronomical tide model, astronomical tide and phase superposition, and database query (i.e., the SONSD) represent the vitally important foundation for the success of the proposed method.

\section{c. The effective multiscenario ensemble prediction based on probability circle}

When the forecasted current track of the TC position deviates markedly from the actual track, there will be substantial 
TABLE 3. As in Table 2, but for Typhoon Maria.

\begin{tabular}{|c|c|c|c|c|c|c|c|}
\hline & & \multicolumn{2}{|c|}{ First HWL } & \multicolumn{2}{|c|}{ Second HWL } & \multicolumn{2}{|c|}{ Third HWL } \\
\hline \multicolumn{2}{|c|}{ Gauge parameter } & $P_{\text {cur }}$ & $P_{\text {ens }}$ & $P_{\text {cur }}$ & $P_{\text {ens }}$ & $P_{\text {cur }}$ & $P_{\text {ens }}$ \\
\hline Sansha $^{a}$ & $\operatorname{HWL}(\mathrm{cm})$ & -8 & -8 & -34 & 6 & - & - \\
\hline & Time (h) & \multicolumn{2}{|c|}{0.30} & \multicolumn{2}{|c|}{0.07} & \multicolumn{2}{|c|}{0.03} \\
\hline \multirow[t]{2}{*}{ Pintan } & HWL & -18 & -18 & -7 & 13 & -61 & 39 \\
\hline & Time (h) & \multicolumn{2}{|c|}{-0.05} & \multicolumn{2}{|c|}{-0.10} & \multicolumn{2}{|c|}{0.18} \\
\hline \multirow[t]{2}{*}{ Chongwu } & HWL $(\mathrm{cm})$ & -32 & -22 & -29 & 16 & -52 & -4 \\
\hline & Time (h) & & & \multicolumn{2}{|c|}{0.58} & \multicolumn{2}{|c|}{0.82} \\
\hline \multirow[t]{2}{*}{ Xiamen } & $\operatorname{HWL}(\mathrm{cm})$ & -51 & -10 & -20 & 5 & -65 & -20 \\
\hline & Time (h) & & & \multicolumn{2}{|c|}{-0.05} & \multicolumn{2}{|c|}{0.28} \\
\hline \multirow[t]{2}{*}{ Dongshan } & $\operatorname{HWL}(\mathrm{cm})$ & -35 & 6 & -26 & -1 & -56 & -36 \\
\hline & Time (h) & & & \multicolumn{2}{|c|}{0.02} & \multicolumn{2}{|c|}{0.38} \\
\hline $\mathrm{ME}$ & HWL $(\mathrm{cm})$ & -27.8 & -10.4 & -23.2 & 7.8 & -58.5 & -5.2 \\
\hline \multirow[t]{2}{*}{ MAE/RMSE } & HWL $(\mathrm{cm})$ & $27.8 / 30.8$ & $12.8 / 14.2$ & $23.2 / 25.0$ & $8.2 / 9.9$ & $58.5 / 58.7$ & $24.8 / 28.4$ \\
\hline & Time (h) & \multicolumn{2}{|c|}{$0.24 / 0.34$} & \multicolumn{2}{|c|}{$0.15 / 0.27$} & \multicolumn{2}{|c|}{$0.42 / 0.43$} \\
\hline
\end{tabular}

${ }^{\mathrm{a}}$ The Sansha gauge was destroyed by the strong wind during Typhoon Maria.

deviation in storm surge predictions based on single forecasted or several scenarios TC track, which could lead to missed warnings or false alarms. As shown in Fig. 10, the actual TC position (i.e., dot "C") at the third HWL time happened at around the time of landfall (i.e., 0910 BT 11 July), which is $3.8 \mathrm{~h}$ ahead of the current TC forecast. The tide in the Taiwan Strait is predominantly semidiurnal (Zhang et al. 2007), as shown in Fig. 14, and the time of landfall was around the time of high tide at Sansha and Pintan stations. The actual storm surge superposed on the high tide generated red and yellow alerts for Sansha and Pintan stations [shown in Fig. 6 (lower)] for Pintan station), respectively, and the Sansha gauge was ultimately destroyed by the high water and strong winds. If a storm surge warning depended only on the single or several scenarios TC track, an alert would not have been issued because the storm surge was superposed around a flat tide. The worst-case scenario may be missed warning within insufficient ensemble members. Therefore, the advantages of ensemble prediction based on probability circle are highlighted by this circumstance because the circle includes all the possible TC positions, considering the uncertainty of not only TC forward direction but also TC speed of movement. With the concept of probability circle, a sufficient number of ensemble members considering the uncertainty of typhoon forecasts were issued in SOSWWS. It could be more robust and reliable to avoid missing warnings than only a few ensemble members (P. T. Wang et al. 2010; Ding et al. 2016; Hasegawa et al. 2017).

In addition to the current and most dangerous forecasted results, time series of prediction results for different tracks (i.e., the current, right, and left tracks) among the multiple

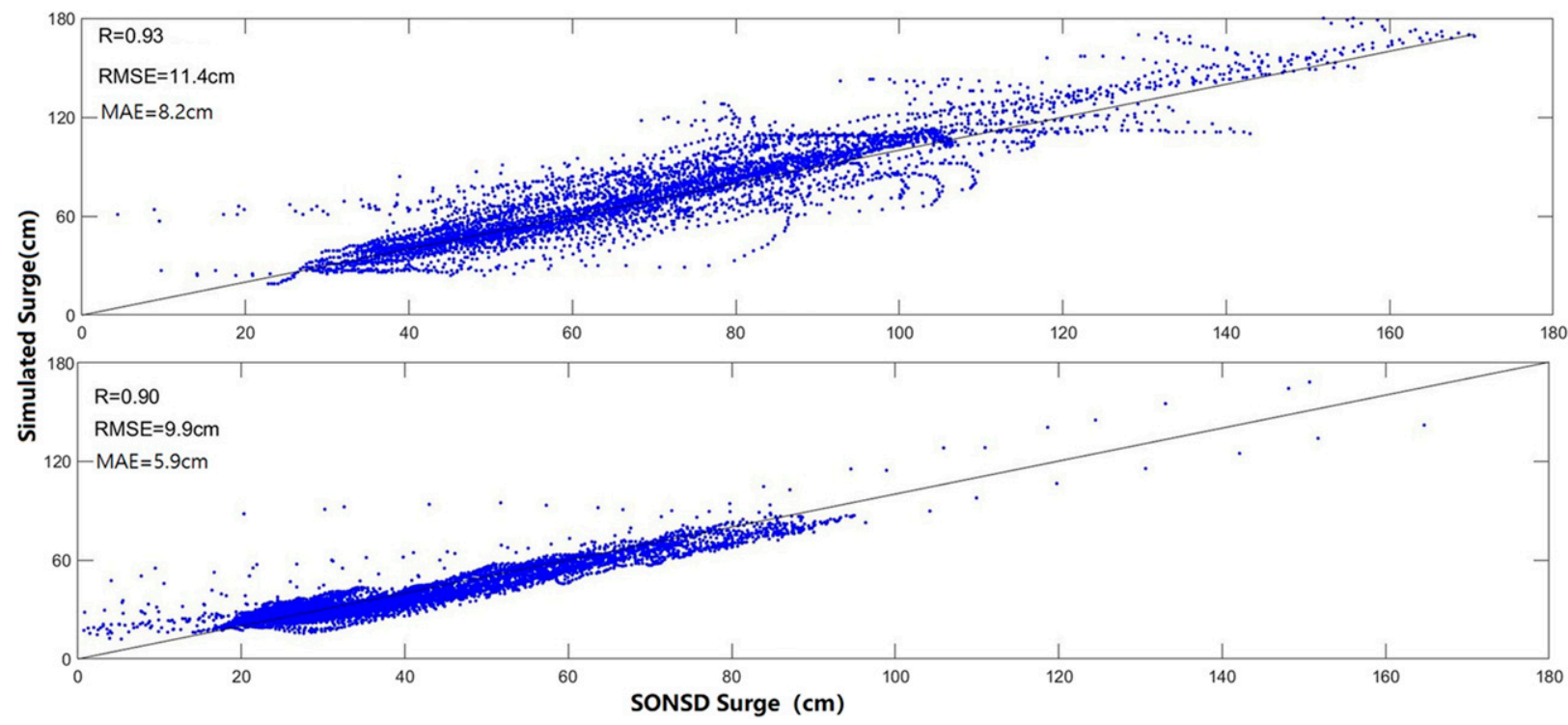

FIG. 12. Comparisons of surge simulated by numerical model and by SONSD for (top) Typhoon Soudelor and (bottom) Maria for 90 seawalls. 


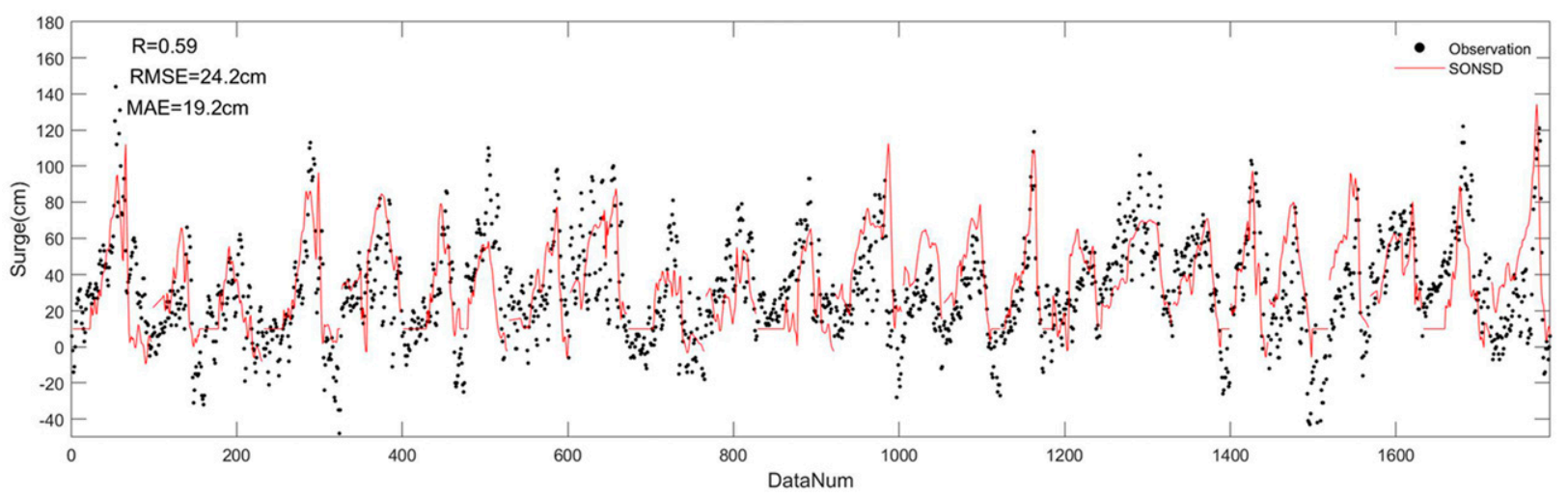

FIG. 13. Comparison of surge predicted by SONSD with observation at Xiamen gauge during 25 historical typhoons.

outcomes are highlighted in different colors in Fig. 6 (lower) as well as the alert levels. Moreover, early warnings and the probabilities of occurrence of overtopping, including the duration of occurrence, along the entire coastline induced by the multiple possible tracks are produced using Eq. (2). Thus, the government and public would better understand the storm surge threat than those systems only issued storm surge distribution map and time series values without comparing to the alert levels (P. T. Wang et al. 2010; Ding et al. 2016; Hasegawa et al. 2017). Yet NHC's public advisories included values of inundation above ground level only if the peak surge occurs at the time of high tide (Forbes et al. 2014). Besides, a forecaster could comprehensively assess the possible TC tracks with consideration of other meteorological factors, realizing water level forecasts and alerts for different possible tracks, which could avoid missed warnings and misinformation.

\section{d. Future work to improve the accuracy of SONSD}

This study developed a method of fast storm surge ensemble prediction for operational application. However, several further steps could be considered in future work to improve the accuracy of SONSD.

When generating hypothetical TCs, the combination of parameters (i.e., track angle, forward speed, and maximum wind speed) was assumed constant for each TC process. These TC parameters, which vary over small ranges at $6-12 \mathrm{~h}$ before landfall, were shown in section $2 \mathrm{c}$ to induce acceptably negligible effects on storm surges. However, this assumption might introduce meaningful error when TC parameters vary markedly in a short time, such as in the case of Soudelor, which twice deviated substantially in its forward direction. The RMSE, MAE, and $R$ values, which were assessed based on a numerical hindcast simulation and the SONSD for forecasts with 12-h lead times during 0800-2000 BT 8 August, were 28.2, $22.2 \mathrm{~cm}$, and 0.64 , respectively (not shown). It demonstrated that when generating perturbed TC tracks, even if a reduced lead time of $12 \mathrm{~h}$ were set for the probability circle in the case of a storm such as Soudelor with a reasonably nonlinear track, the performance of the surge calculation based on the SONSD approach would still be relatively weak owing to the sensitivity to TC direction. Therefore, one expectation for future work is to dynamically generate hypothetical TCs that more closely reflect the actual situation.

When calculating the synthetic database, the radius of maximum wind speed, which is one of the most critical parameters for describing the storm extent, is not used presently as a separate parameter because it is not given directly in a TC forecast. Although a formula corresponding to $W_{\max }$ and latitude was used, the size of a TC wind field varies significantly from storm to storm and during the life cycle of an individual TC (Cangialosi and Landsea 2016). This could introduce major errors when the structure of a TC varies markedly from statistical values. The NHC analyzes and forecasts TC size in four quadrants at the $34-, 50-$, and $64-\mathrm{kt}\left(1 \mathrm{kt} \approx 0.51 \mathrm{~m} \mathrm{~s}^{-1}\right)$ wind thresholds. The CMA also issues these radii during a TC process but does not correct them afterward. These radii were used to improve the accuracy of TC wind fields by Zhang et al. (2014), based on the work of Jelesnianski (1965). They have also been used as partial inputs in ANN methods to interpret the results of numerical models of storm surge (Zhang et al. 2016) for several TC cases. However, the addition of another such variable (i.e., wind radii at five intervals) to the combination used for the hypothetical TCs would increase the size of the scenario storm surge database by five times the current size (i.e., up to $20 \mathrm{~GB}$ ), which could be too large for practical application. Recently, storm surge prediction using ANNs was undertaken by our research group based on the numerical scenario storm surge database established in this study. It is expected that prediction of the wind radii could be used to interpret the calculation results of the CI-based method in future study. Therefore, storm surge prediction accuracy could be improved both by consideration of TC size, and by developments in computational efficiency attributable to soft computational technology.

The nonlinear interaction between tide and storm surge is considered negligible in the proposed method, which could lead to error in the total water level determined by linear superposition of the storm surge on the tide. However, the small magnitude of the error is acceptably negligible in comparison with the tide prediction error of numerical models (Flowerdew et al. 2010) for the case study area. Nevertheless, the spatiotemporal characteristics of the nonlinear interaction should be examined carefully in application of the method to other areas. 

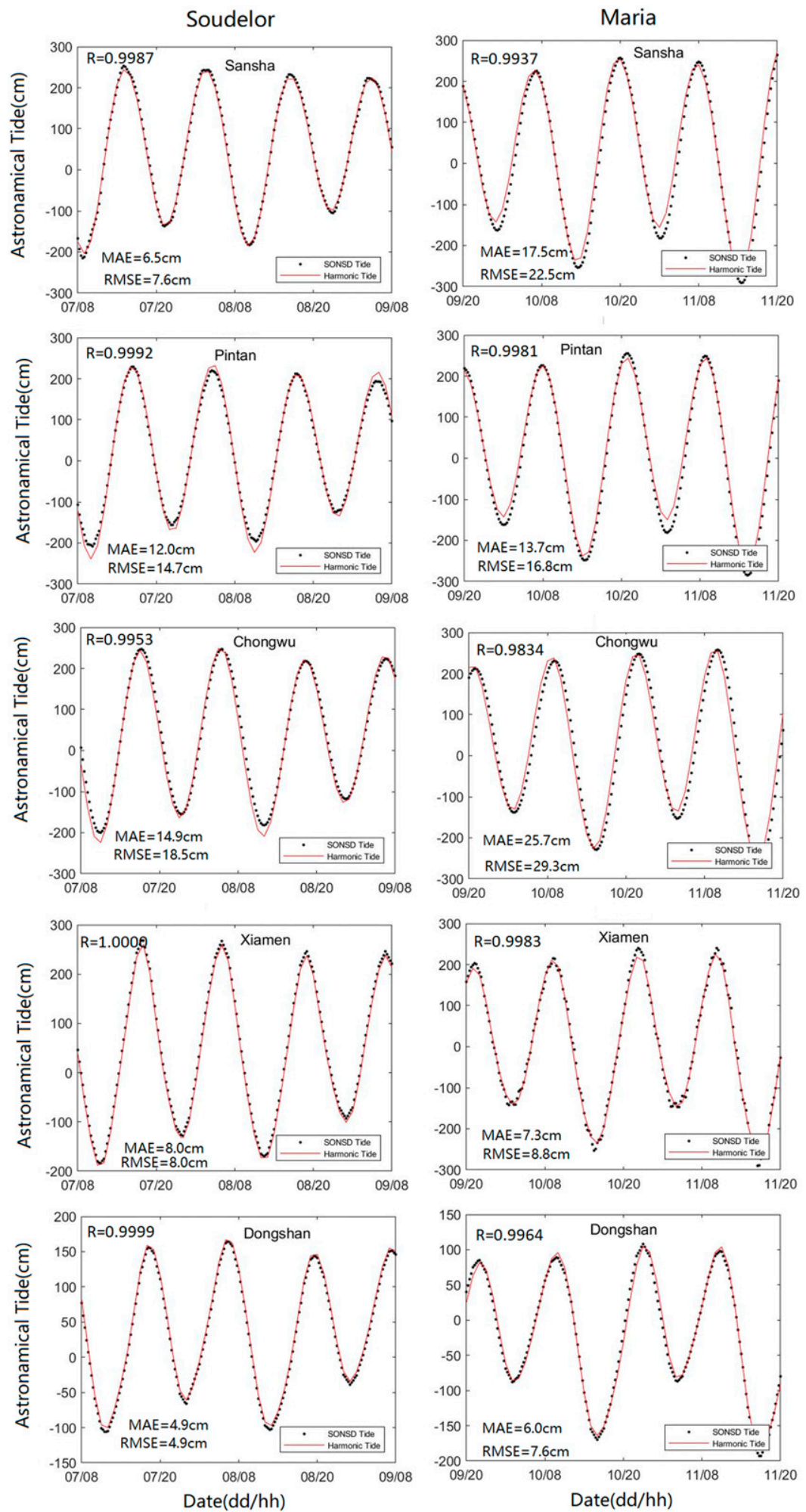

FIG. 14. Time series of harmonic tide (solid dots) and SONSD tide level (red solid lines) of (left) Typhoon Soudelor and (right) Typhoon Maria at five gauge stations. 
Finally, additional cases should be studied to verify the assessment of the improvement realized by the SONSD prediction results.

\section{Conclusions}

The SONSD method, which is proposed for fast ensemble forecasting, has been applied successfully by Fujian Marine Forecasts and at Ningbo Hydrological Station (Zhejiang Province) (Xie et al. 2015), which are areas on China's coast that are affected by storm surge disasters annually. It only takes $1-2 \mathrm{~min}$ for this system to produce results, from taking a typhoon advisory to visualizing warning products, using a commonly available PC. The prediction results for the case studies of Typhoon Soudelor and Typhoon Maria showed high accuracy equivalent to a high-resolution numerical model based on the correct typhoon forecast, and effectively helped avoid missed warnings when the typhoon forecast deviation was large. The success of the application proves that the method is suitably generalized. Furthermore, verification results of the searching accuracy by comparing predicted values due to SONSD with numerical model as well as observed ones indicated comparable errors to numerical model. Thus, it should be possible to establish a numerical scenario storm surge database and an astronomical tide dataset using a wellcalibrated high-resolution model to calculate storm surges generated by multiple hypothetical TCs in other research areas. The visualization system (i.e., SOSWWS) established based on this method, which contains forecast probabilities for exceedance of relevant thresholds, could provide swift response to the emergency management need and deliver reliable decision-making support.

Acknowledgments. This work was funded by two grants from the National Key Research and Development Project of China (Grants 2017YFC1404801 and 2016YFC1401104) and the Marine Economic Development Subsidy Project of Fujian, China (Grant ZHHY-2019-2). We are grateful to Fujian Marine Forecasts for supplying the tide gauge data. We thank Sichuang Technology Co., Ltd. for establishing the SOSWWS software. We thank Professor Yan Li from Xiamen University for suggestions regarding the proposed method presented in this paper. We thank James Buxton MSc from Liwen Bianji, Edanz Group China (www.liwenbianji.cn./ac), for editing the English text of this manuscript.

\section{REFERENCES}

Atkinson, G. D., and C. R. Holliday, 1977: Tropical cyclone minimum sea level pressure/maximum sustained wind relationship for the western North Pacific. Mon. Wea. Rev., 105, 421-427, https:// doi.org/10.1175/1520-0493(1977)105<0421:TCMSLP>2.0.CO;2.

Bloemendaal, N., S. Muis, R. J. Haarsma, M. Verlaan, M. I. Apecechea, H. De Moel, P. J. Ward, and J. C. Aerts, 2019: Global modeling of tropical cyclone storm surges using highresolution forecasts. Climate Dyn., 52, 5031-5044, https:// doi.org/10.1007/s00382-018-4430-x.

Bode, L., and T. A. Hardy, 1997: Progress and recent developments in storm surge modeling. ASCE J. Hydraul. Eng., 123, 315-331, https://doi.org/10.1061/(ASCE)0733-9429(1997)123:4(315).
Bonnardot, F., and Coauthors, 2016: An integrated tool for forecasting tropical cyclone induced floods: The SPICY project. 32nd Conf. on Hurricanes and Tropical Meteorology, San Juan, Puerto Rico, Amer. Meteor. Soc., https://ams.confex.com/ ams/32Hurr/webprogram/Paper293168.html.

Cangialosi, J. P., 2019: National Hurricane Center forecast verification report: 2019 hurricane season. National Hurricane Center Rep., 75 pp., www.nhc.noaa.gov/verification/pdfs/ Verification_2019.pdf.

_ , and C. W. Landsea, 2016: An examination of model and official National Hurricane Center tropical cyclone size forecasts. Wea. Forecasting, 31, 1293-1300, https://doi.org/10.1175/ WAF-D-15-0158.1.

Chao, W. T., C. C. Young, T. W. Hsu, W. C. Liu, and C. Y. Liu, 2020: Long-lead-time prediction of storm surge using artificial neural networks and effective typhoon parameters: Revisit and deeper insight. Water, 12, 2394, https://doi.org/10.3390/ w12092394.

Chen, C. S., R. C. Beardsley, and G. Cowles, 2006: An unstructured grid, finite-volume coastal ocean model (FVCOM) system. Oceanography, 19, 78-89, https://doi.org/10.5670/oceanog.2006.92.

Chen, D. W., 2006: Analysis and modeling study of typhoon sea surface wind field in the vicinity of Taiwan. M.S. thesis, College of Ocean and Earth Science, Xiamen University, 108 pp., http://cdmd.cnki.com.cn/article/cdmd-10384-2007055729.htm.

Chen, G. M., X. P. Zhang, L. N. Bai, and R. J. Wan, 2019: Verification on forecasts of tropical cyclones over Western North Pacific and South China Sea in 2017 (in Chinese). Meteor. Mon., 45, 577-586, https://doi.org/10.7519/j.issn.10000526.2019.04.012.

Ding, X. L., Y. P. Chen, Y. Pan, and D. Reeve, 2016: Fast ensemble forecast of storm surge along the coast of China. J. Coastal Res., 75, 1077-1081, https://doi.org/10.2112/SI75-216.1.

Dube, S. K., I. Jain, A. D. Rao, and T. S. Murty, 2009: Storm surge modelling for the Bay of Bengal and Arabian Sea. Nat. Hazards, 51, 3-27, https://doi.org/10.1007/s11069-009-9397-9.

Feng, X., M. Li, B. Yin, D. Yang, and H. Yang, 2018: Study of storm surge trends in typhoon-prone coastal areas based on observations and surge-wave coupled simulations. Int. J. Appl. Earth Obs. Geoinfo., 68, 272-278, https://doi.org/10.1016/ j.jag.2018.01.006.

Flowerdew, J., K. Horsburgh, and K. Mylne, 2009: Ensemble forecasting of storm surges. Mar. Geod., 32, 91-99, https:// doi.org/10.1080/01490410902869151.

—_ — C. C. Wilson, and K. Mylne, 2010: Development and evaluation of an ensemble forecasting system for coastal storm surges. Quart. J. Roy. Meteor. Soc., 136, 1444-1456, https:// doi.org/10.1002/qj.648.

Forbes, C., J. Rhome, C. Mattocks, and A. Taylor, 2014: Predicting the storm surge threat of hurricane sandy with the National Weather Service SLOSH model. J. Mar. Sci. Eng., 2, 437-476, https://doi.org/10.3390/jmse2020437.

Fotovatikhah, F., M. Herrera, S. Shamshirband, K. W. Chau, S. Faizollahzadeh Ardabili, and M. J. Piran, 2018: Survey of computational intelligence as basis to big flood management: Challenges, research directions and future work. Eng. Appl. Comp. Fluid Mech., 12, 411-437, https://doi.org/10.1080/ 19942060.2018.1448896.

Greenslade, D., and Coauthors, 2017: An operational coastal sea level forecasting system. 16th Australasian Port and Harbour Conf:: Working with Nature, Cairns, Queensland, Australia, Engineers Australia, PIANC Australia and Institute of Professional Engineers New Zealand, 514-520. 
Hasegawa, H., N. Kohno, and H. Hayashibara, 2012: JMA's storm surge prediction for the WMO Storm Surge Watch Scheme (SSWS). Tech. Rev. 14, RSMC Tokyo-Typhoon Center, 12 pp., http://www.jma.go.jp/jma/jma-eng/jma-center/ rsmc-hp-pub-eg/techrev/text14-2.pdf.

,,-- M. Higaki, and M. Itoh, 2017: Upgrade of JMA's storm surge prediction for the WMO Storm Surge Watch Scheme (SSWS). Tech. Rev. 19, RSMC Tokyo-Typhoon Center, 9 pp., http://www.jma.go.jp/jma/jma-eng/jma-center/rsmc-hp-pub-eg/ techrev/text19-2.pdf.

Holland, G. J., 1980: An analytic model of the wind and pressure profiles in hurricanes. Mon. Wea. Rev., 108, 1212-1218, https://doi.org/10.1175/1520-0493(1980)108<1212:AAMOTW > 2.0.CO;2.

Homsi, R., M. S. Shiru, S. Shahid, T. Ismail, S. B. Harun, N. AlAnsari, and K. W. Chao, 2020: Precipitation projection using a CMIP5 GCM ensemble model: A regional investigation of Syria. Eng. Appl. Comp. Fluid Mech., 14, 90-106, https:// doi.org/10.1080/19942060.2019.1683076.

Horsburgh, K. J., and C. Wilson, 2007: Tide-surge interaction and its role in the distribution of surge residuals in the North Sea. J. Geophys. Res., 112, C08003, https://doi.org/10.1029/ 2006JC004033.

Hsu, S. A., and Z. D. Yan, 1998: A note on the radius of maximum wind for hurricanes. J. Coastal Res., 14, 667-668, https:// www.jstor.org/stable/4298820.

Irish, J. L., D. T. Resio, and J. J. Ratcliff, 2008: The influence of storm size on hurricane surge. J. Phys. Oceanogr., 38, 20032013, https://doi.org/10.1175/2008JPO3727.1.

— C. Ferreira, F. Olivera, I. Udoh, Y. K. Song, and K. A. Chang, 2010: Rapid probabilistic hurricane surge and damage forecasting using surge response functions. Coastal Eng., 32, https://doi.org/10.9753/icce.v32.currents.20.

_ - Y. K. Song, and K. A. Chang, 2011: Probabilistic hurricane surge forecasting using parameterized surge response functions. Geophys. Res. Lett., 38, 250-257, https://doi.org/10.1029/ 2010 GL046347.

Jakobsen, F., and H. Madsen, 2004: Comparison and further development of parametric tropical cyclone models for storm surge modelling. J. Wind Eng. Ind. Aerodyn., 92, 375-391, https://doi.org/10.1016/j.jweia.2004.01.003.

Jelesnianski, C. P., 1965: A numerical calculation of storm tides induced by a tropical storm impinging on a continental shelf. Mon. Wea. Rev., 93, 343-358, https://doi.org/10.1175/15200493(1993)093<0343:ANCOS > 2.3.CO;2.

JMA, 2019: Annual report on the activities of the RSMC TokyoTyphoon Center 2019. Japan Meteorological Agency, 115 pp., https://www.jma.go.jp/jma/jma-eng/jma-center/rsmc-hp-pub-eg/ AnnualReport/2019/Text/Text2019.pdf.

Kaya, C. M., G. Tayfur, and O. Gungor, 2019: Predicting flood plain inundation for natural channels having no upstream gauged stations. J. Water Climate Change, 10, 360-372, https:// doi.org/10.2166/wcc.2017.307.

Kentang, L., 2000: An analysis of the recent severe storm surge disaster events in China. Nat. Hazards, 21, 215-223, https:// doi.org/10.1023/A:1008077621186.

Keum, H. J., K. Y. Han, and H. I. Kim, 2020: Real-time flood disaster prediction system by applying machine learning technique. KSCE J. Civil Eng., 24, 2835-2848, https://doi.org/ 10.1007/s12205-020-1677-7.

Kim, S. Y., T. Yasuda, and H. Mase, 2008: Numerical analysis of the effects of tidal variations on storm surges and waves. Appl. Ocean Res., 30, 311-322, https://doi.org/10.1016/j.apor.2009.02.003.
- N. Mori, H. Mase, and T. Yasuda, 2015: The role of sea surface drag in a coupled surge and wave model for Typhoon Haiyan 2013. Ocean Modell., 96, 65-84, https://doi.org/10.1016/ j.ocemod.2015.06.004.

_ - S. Pan, and H. Mase, 2019: Artificial neural network-based storm surge forecast model: Practical application to Sakai Minato, Japan. Appl. Ocean Res., 91, 101871, https://doi.org/ 10.1016/j.apor.2019.101871.

Kohno, N., S. K. Dube, M. Entel, S. H. M. Fakhruddin, D. Greenslade, M. Leroux, J. Rhome, and N. B. Thuy, 2018: Recent progress in storm surge forecasting. Trop. Cyclone Res. Rev., 7, 55-66.

Krishnamurti, T. N., C. M. Kishtawal, T. E. Larow, D. R. Bachiochi, Z. Zhang, C. E. Williford, S. Gadgil, and S. Surendran, 1999: Improved weather and seasonal climate forecasts from multimodel superensemble. Science, 285, 1548-1550, https://doi.org/ 10.1126/science.285.5433.1548.

Landsea, C. W., and J. P. Cangialosi, 2018: Have we reached the limits of predictability for tropical cyclone track forecasting? Bull. Amer. Meteor. Soc., 99, 2237-2243, https://doi.org/10.1175/ BAMS-D-17-0136.1.

Luettich, R. A., and J. J. Westerink, 2004: Formulation and numerical implementation of the 2D/3D ADCIRC finite element model version 44.XX. 74 pp., https://adcirc.org/wp-content/uploads/ sites/2255/2018/11/2004_Luettich.pdf.

Majumdar, S. J., J. Sharanya, M. Peter, and P. M. Finocchio, 2010: On the ability of global ensemble prediction systems to predict tropical cyclone track probabilities. Wea. Forecasting, 25, 659680, https://doi.org/10.1175/2009WAF2222327.1.

Mattocks, C., and C. Forbes, 2008: A real-time event-triggered storm surge forecasting system for the state of North Carolina. Ocean Modell., 25, 95-119, https://doi.org/10.1016/j.ocemod.2008.06.008.

Ministry of Ecology and Environment, 2020: Bulletin of Marine Ecology and Environment Status of China in 2019. Ministry of Ecology and Environment, 47 pp., http://english.mee.gov.cn/Resources/Reports/ bomeaesoc/202012/P020201225370164112761.pdf.

Needham, H. F., B. D. Keim, and D. Sathiaraj, 2015: A review of tropical cyclone-generated storm surges: Global data sources, observations, and impacts. Rev. Geophys., 53, 545-591, https:// doi.org/10.1002/2014RG000477.

Niedoroda, A. W., D. T. Resio, G. R. Toro, D. Divoky, H. S. Das, and C.W. Reed, 2010: Analysis of the coastal Mississippi storm surge hazard. Ocean Eng., 37, 82-90, https://doi.org/10.1016/ j.oceaneng.2009.08.019.

Nobutaka, M., 2005: Reduction of the radius of probability circle in Typhoon track forecast. Tech. Rev. 8, RSMC Tokyo-Typhoon Center, 9 pp., https://www.jma.go.jp/jma/jma-eng/jma-center/ rsmc-hp-pub-eg/techrev/text8-1.pdf.

Suh, S. W., H. Y. Lee, H. J. Kim, and J. G. Fleming, 2015: An efficient early warning system for typhoon storm surge based on timevarying advisories by coupled ADCIRC and SWAN. Ocean Dyn., 65, 617-646, https://doi.org/10.1007/s10236-015-0820-3.

Taormina, R., and K. W. Chau, 2015: Ann-based interval forecasting of streamflow discharges using the LUBE method and MOFIPS. Eng. Appl. Artif. Intell., 45, 429-440, https://doi.org/ 10.1016/j.engappai.2015.07.019.

Tseng, C. M., C. D. Jan, J. S. Wang, and C. Wang, 2007: Application of artificial neural networks in typhoon surge forecasting. Ocean Eng., 34, 1757-1768, https://doi.org/10.1016/ j.oceaneng.2006.09.005.

Wang, D. F., H. S. Hong, S. P. Shang, J. Q. Chen, Y. S. Xie, and Y. Wei, 2010: A numerical model for tide forecasting from assimilation of tide table data and its forecasting results. J. Oceanogr. Taiwan, 29, 263-270. 
Wang, P. T., F. J. Yu, Q. X. Liu, and J. X. Dong, 2010: Studies and applications on refined ensemble numerical Typhoon surge forecast technology in Fujian Coast. Mar. Forecasts, 27, 7-15.

Westerink, J. J., and Coauthors, 2008: A basin to channel scale unstructured grid hurricane storm surge model as implemented for southern Louisiana. Mon. Wea. Rev., 136, 833-864, https:// doi.org/10.1175/2007MWR1946.1.

Willoughby, H. E., and M. E. Rahn, 2004: Parametric representation of the primary hurricane vortex. Part I: Observations and evaluation of the Holland (1980) model. Mon. Wea. Rev., 132, 3033-3048, https://doi.org/10.1175/MWR2831.1.

Wu, C. L., and K. W. Chau, 2013: Prediction of rainfall time series using modular soft computing methods. Eng. Appl. Artif. Intell., 26, 997-1007, https://doi.org/10.1016/j.engappai.2012.05.023.

Xie, Y. S., S. P. Shang, and D. F. Wang, 2009: Numerical experiments of storm surge along Fujian coast. J. Xiamen Univ., 48 , 714-718.

,$- \ldots$, F. Zhang, and L. Zhang, 2015: Use of a storm surge overbank warning assistant decision system for Ningbo city. J. Appl. Oceanogr., 34, 467-475, https://doi.org/10.3969/ J.ISSN.2095-4972.2015.04.002.

Yang, H. T., S. Z. Tian, L. Ye, and F. X. Xu, 1993: Catalog of Marine and Coastal Disasters in China (1949-1990). China Ocean Press, 288 pp.
Ying, M., W. Zhang, H. Yu, X. Lu, J. Feng, and Y. Fan, 2014: An overview of the China Meteorological Administration tropical cyclone database. J. Atmos. Oceanic Technol., 31, 287-301, https://doi.org/10.1175/JTECH-D-12-00119.1.

Zhang, J., S. H. Zhou, B. X. Huang, and M. Zhang, 2016: Interpretation of numerical storm surge model results using the artificial neural network. Mar. Forecasts, 33, 60-65, https:// doi.org/10.11737/j.issn.1003-0239.2016.02.009.

Zhang, L., S. P. Shang, F. Zhang, and Y. S. Xie, 2020: Tide-surgewave interaction in the Taiwan Strait during typhoons Soudelor (2015) and Dujuan (2015). Appl. Sci., 10, 7382, https://doi.org/ 10.3390/app10207382.

Zhang, S. F., C. H. Qian, S. Z. Gao, and Z. K. Liu, 2010: Application of probability circle for tropical cyclone track forecast. Meteor. Sci. Technol., 38, 159-164, https://doi.org/ 10.19517/j.1671-6345.2010.02.003.

Zhang, W. Z., H. S. Hong, S. P. Shang, D. W. Chen, and F. Chai, 2007: A two-way nested coupled tide-surge model for the Taiwan Strait. Cont. Shelf Res., 27, 1548-1567, https://doi.org/ 10.1016/j.csr.2007.01.018.

Zhang, Y. D., S. P. Shang, Y. S. Xie, Z. Li, K. R. Yuan, and F. Zhang, 2014: Typhoon wind field model based on the radii of wind circle. J. Xiamen Univ., 53, 98-103, https://doi.org/ 10.6043/j.issn.0438-0479.2014.02.001. 